\title{
Age-Related Resistance of Nicotiana benthamiana Against Hemibiotrophic Pathogen Phytophthora infestans Requires Both Ethylene- and Salicylic Acid-Mediated Signaling Pathways
}

\author{
Yusuke Shibata, Kazuhito Kawakita, and Daigo Takemoto \\ Plant Pathology Laboratory, Graduate School of Bioagricultural Sciences, Nagoya University, Chikusa, Nagoya, 464-8601, \\ Japan
}

Submitted 14 February 2010. Accepted 13 May 2010.

\begin{abstract}
Phytophthora infestans, the agent of late blight disease of potato, is a hemibiotrophic pathogen with biotrophic action during early infection and necrotrophic in the later stage of colonization. Mature Nicotiana benthamiana was resistant to $P$. infestans, whereas relatively young plants were susceptible to this pathogen. Young plants became resistant following a pretreatment with acibenzolar- $S$-methyl, a functional analog of salicylic acid (SA), indicating that susceptibility of young plants is due to a lack of induction of SA signaling. Further analysis with virus-induced gene silencing indicated that NbICS1 and NbEIN2, the genes for SA biosynthesis and ethylene (ET) signaling, respectively, are required for the resistance of mature $N$. benthamiana against $P$. infestans. Furthermore, these genes are required for the production of reactive oxygen species (ROS) induced by treatment of the INF1 elicitor. In NbICS1-silenced plants, cell death induced by either INF1 or necrosis-inducing protein NPP1.1 was significantly accelerated. Expression of genes for phytoalexin (capsidiol) biosynthesis, $N b E A S$ and $N b E A H$, were regulated by ET, and gene silencing of either of them compromised resistance of $N$. benthamiana to $P$. infestans. Together, these results suggest that resistance of $N$. benthamiana against hemibiotrophic $P$. infestans requires both $\mathrm{SA}$-regulated appropriate induction of cell death and ET-induced production of phytoalexin.
\end{abstract}

The oomycete pathogen, Phytophthora infestans, is the causal agent of potato late blight, which is one of the most destructive and economically important plant diseases worldwide. $P$. infestans is historically significant as a cause of the Irish potato famine in the $1840 \mathrm{~s}$, and this pathogen still causes a 10 to $15 \%$ reduction in the annual global potato production (CIP 1996). More than 10 dominant race-specific resistance $(R)$ genes have been discovered in the wild species Solanum demissum, and some of these were introgressed into potato cultivars. However, $R$-gene-dependent resistances were quickly overcome by emerging new isolates of the pathogen (Umaerus and Umaerus 1994). Relatively recently, $R$ genes conferring

Corresponding author: Daigo Takemoto; Telephone: +81 52789 4029; Fax: +81 52789 5525; E-mail: dtakemo@agr.nagoya-u.ac.jp

* The $\boldsymbol{e}$-Xtra logo stands for "electronic extra" and indicates that one supplementary table and six supplementary figures are published online. Also, Figures 3 and 4 appear in color online. broad-spectrum resistance to $P$. infestans have been identified from several wild Solanum spp., such as RB/Rpi-blbl and Rpiblb2 from $S$. bulbocastanum (Song et al. 2003; van der Vossen et al. 2005) and Rpi-pntl from S. pinnatisectum (Kuhl et al. 2001). Introduction of these resistance to P. infestans (Rpi) genes into cultivated potato lines is considered the most practical approach to achieving durable resistance of potato plants against $P$. infestans.

Race-specific and broad-spectrum $R$ genes generally induce a similar set of resistance reactions in response to a pathogen attack involving corresponding avirulence factors. These responses include production of physical and chemical barriers at the site of pathogen attack, accumulation of antimicrobial proteins and secondary metabolites, and the induction of hypersensitive cell death, a form of plant-programmed cell death that confines the attacking pathogen to the site of infection (Hahlbrock et al. 2003; Jones and Takemoto 2004). Production of reactive oxygen species (ROS) is characteristic of plant resistance reactions, and they are thought to act as second messengers for the induction of resistance reactions, such as the expression of defense genes and induction of hypersensitive cell death (or hypersensitive reactions [HR]) (Doke et al. 1996; Yoshioka et al. 2003; Yoshie et al. 2005). Induction of disease resistance is generally accompanied by activation of several signal transduction pathways mediated by "phytohormones" such as salicylic acid (SA), jasmonic acid (JA), and ethylene (ET) (Glazebrook 2005). Extensive research using the Brassicaceous model plant Arabidopsis thaliana with various pathogens revealed that resistances to biotrophic and necrotrophic pathogens require different sets of defense reactions to effectively prevent their infection and colonization. Arabidopsis mutants with impaired SA signaling (i.e., sid2 and eds5) failed to induce effective resistance against the biotrophic oomycete pathogen Hyaloperonospora arabidopsidis, whereas these mutants were totally resistant to necrotrophic Alternaria brassicicola and Botrytis cinerea (Nawrath and Métraux 1999; Ferrari et al. 2003; van Wees et al. 2003). In contrast, mutation of JA signaling (i.e., coil) or phytoalexin (camalexin) production (i.e., pad3) compromised resistance to necrotrophic pathogens, whereas these mutants retained resistance to biotrophic $H$. arabidopsidis infection (Glazebrook et al. 1997; Thomma et al. 1999; Ferrari et al. 2003; van Wees et al. 2003). Based on these reports, it is generally considered that SA signaling is involved in resistance to biotrophic pathogens, whereas JA signaling is essential to stop infection by necrotrophic pathogens (McDowell and Dangl 2000; Glazebrook 2005). 
P. infestans is a hemibiotrophic plant pathogen; it behaves as a biotrophic pathogen in the early stage of infection but acts as a necrotrophic pathogen in the late stage of colonization. Despite the practical importance of this pathogen, signaling pathways required for plant resistance against $P$. infestans are largely unknown, because of the lack of an appropriate plant model to investigate host-pathogen interactions. In artificial interactions between Arabidopsis and P. infestans, most of the penetration attempts by $P$. infestans ceased at the surface of the plant cell. Arabidopsis pen 2 and pen3 mutants inoculated with $P$. infestans showed reduced penetration resistance accompanied with hypersensitive cell death at the site of infection. This indicated that penetration resistance is a major factor for the resistance of Arabidopsis against inappropriate pathogen $P$. infestans, which is supported by a post-invasion defense mechanism (Lipka et al. 2005; Kobae et al. 2006; Stein et al. 2006).

$P$. infestans is a pathogen for Solanaceous potato and tomato but most of Solanaceous spp., except potato and tomato, are generally resistant to $P$. infestans infection. The wild Nicotiana sp., Nicotiana benthamiana, is a Solanaceous model plant which can be applied for functional analysis of genes by manipulating expression level of genes of interest using Agrobacterium sp.-mediated transient gene expression or virus-induced gene silencing (VIGS) (Ratcliff et al. 2001). N. benthamiana is a good candidate as a model plant to analyze resistance reactions of Solanaceous plant against $P$. infestans. However, there are contradictory reports about interaction between $P$. infestans and $N$. benthamiana. Some reports indicated that $N$. benthamiana is resistant to $P$. infestans (Kamoun et al. 1998; Yoshioka et al. 2003), whereas others reported that $N$. benthamiana is susceptible to this pathogen (Becktell et al. 2006; Asai et al. 2008). These conflicting observations could be a result of conditional differences in $P$. infestans inoculation or differences in age of $N$. benthamiana or $P$. infestans isolates used in these studies.

The objectives of this research were to i) clarify the nature of the interaction between $P$. infestans and N. benthamiana, ii) identify the essential signal transduction pathways for $N$. benthamiana resistance to $P$. infestans infection, and iii) identify the genes or phenomena regulated by signal transduction pathways required for resistance to $P$. infestans. This allows an overview of the basis of $N$. benthamiana resistance to infection by hemibiotrophic pathogen $P$. infestans.

\section{RESULTS}

\section{Age-related resistance}

of $N$. benthamiana against $P$. infestans.

To investigate the nature of the interaction between $N$. benthamiana and $P$. infestans, $N$. benthamiana plants at different stages of growth were inoculated with $P$. infestans isolate PI01 (race 0 ). Within 5 days after the inoculation of $P$. infestans, relatively young plants (20 to 25 days from the date of sowing) showed water-soaked disease symptoms on inoculated leaves (Fig. 1A), and the disease lesions almost extended over entire leaves within 14 days. In contrast, mature $N$. benthamiana plants (35 to 40 days old) were completely resistant to $P$. infestans (Fig. 1A and 1C). Most of the 30-day-old plants were resistant and only occasionally showed disease symptoms (Fig. 1C). These results indicated that resistance of $N$. benthamiana plants against $P$. infestans is dependent on their age. The interaction between $P$. infestans and young or mature $N$. benthamiana was examined using light microscopy, after staining with lactophenol trypan blue of inoculated leaves (staining of plant cells with trypan blue is indicative of cell death). In the interaction between $P$. infestans and mature $N$. benthamiana, a few densely stained epidermal and mesophyll cells under the pene- tration site of $P$. infestans were observed from $12 \mathrm{~h}$ after inoculation. By $48 \mathrm{~h}$ after inoculation, there was no detectable mycelium growth of $P$. infestans within and around clusters of approximately five dead mesophyll cells (Fig. 1D). On young leaves inoculated with $P$. infestans, most of the encysted zoospores and zoosporangia had germinated and developed appressorium-like swellings that formed preferentially over anticlinal walls between epidermal cells at $6 \mathrm{~h}$ after inoculation (Fig. 1E). By $24 \mathrm{~h}$ after inoculation, extensive growth of $P$. infestans hyphae in intercellular spaces of mesophyll cells, with formation of finger-like haustoria, was observed. Corruption of a large number of mesophyll cells was observed where there was massive infection at 36 and $48 \mathrm{~h}$ after inoculation (Fig. 1E), indicating that transition from the biotrophic to necrotrophic phase of $P$. infestans infection occurred between 24 and $36 \mathrm{~h}$ after inoculation in interaction with young $N$. benthamiana. We also applied six additional isolates of $P$. infestans to test the resistance of $N$. benthamiana. All tested $P$. infestans isolates produced disease symptoms on 20- to 25-day-old $N$. benthamiana plants but mature plants were resistant to all isolates (Y. Shibata and D. Takemoto, unpublished data). These results confirmed that $N$. benthamiana has age-related resistance against $P$. infestans, and there is probably no fundamental difference in pathogenicity between isolates of $P$. infestans. Consequently, for subsequent analyses, we studied the interaction of 35-day-old $N$. benthamiana plants and $P$. infestans isolate PI0-1 unless otherwise noted.

\section{Both SA- and ET-mediated signaling are essential for resistance of $N$. benthamiana to $P$. infestans.}

To investigate the role of signaling pathways on resistance of $N$. benthamiana to $P$. infestans, VIGS was applied to knockdown genes involved in SA-, ET-, or JA-mediated signaling pathways. Gene fragments of $N$. benthamiana homologues of A. thaliana SA induction-deficient 2/isochorismate synthase 1 (SID2/ICS1) (Wildermuth et al. 2001), nonexpresser of pathogenesis-related $(P R)$ genes (NPRl) (Cao et al. 1997), colonatin insensitive 1 (COII) (Xie et al. 1998), and ET-insensitive 2 (EIN2) (Alonso et al. 1999) were isolated by reverse-transcription polymerase chain reaction (RT-PCR) and cloned into the vector for Tobacco rattle virus (TRV)-mediated VIGS, pTV00 (Ratcliff et al. 2001). In leaves of $N$. benthamiana, expression of $N b I C S 1$ and $N b N P R I$ was induced by treatment with INF1, a secretory elicitor protein derived from $P$. infestans, while $\mathrm{NbCOI1}$ and NbEIN2 showed constitutive expression (Supplementary Fig. 1) (Kamoun et al. 1997). Expression of these genes was silenced by VIGS, and genesilenced $N$. benthamiana were inoculated with $P$. infestans isolate PI0-1. It was confirmed that expression of target genes was suppressed in VIGS-induced plants treated with INF1 (Fig. 2A). All gene-silenced plants showed normal growth compared with the control TRV-infected plant, although the NbICS1-silenced plant showed weak chlorosis. This was consistent with previous reports, because isochorismate is the precursor for the biosynthesis of phylloquinone as well as SA and, consequently, mutation of the ICS1 gene causes a reduction in photosystem I (PSI) activity and chlorophyll accumulation (Gross et al. 2006, Catinot et al. 2008). Within 2 days after the inoculation, NbICS1- and NbEIN2silenced plant started to show the development of visible disease symptoms on the inoculated area, and the expansion of lesions beyond the inoculated area occurred over the period of observation (Fig. 2B). In contrast, NbNPRI- and NbCOIIsilenced $N$. benthamiana showed complete resistance against $P$. infestans, comparable with the control TRV-infected plant. Extension of $P$. infestans hyphae in planta and dead plant cells around infection sites were visualized by staining with lacto- 
phenol-trypan blue. At $48 \mathrm{~h}$ after inoculation, HR-like local death of plant epidermal and mesophyll cells was occasionally observed at infection sites of the control, NbNPRI-, and NbCOI1-silenced $N$. benthamiana plants (Fig. 2C). In NbICS1- or NbEIN2-silenced N. benthamiana plants, the bulk of the dead mesophyll cells were obvious around the original site of infection; however, $P$. infestans hyphae near the edge of lesions were generally not enclosed by the dead plant cells (Fig. 2C). Reduced resistance of NbICS1- or NbEIN2-silenced plants was scored by visible development of disease symptoms (Fig. 2D). Both NbICS1- and NbEIN2-silenced plants showed a significant reduction in resistance against $P$. infestans, although we consistently observed that NbEIN2-silenced plants showed faster development of disease symptoms compared with NbICS1-silenced plants (Fig. 2D). These results indicated that both SA- and ET-signaling pathways are essential for $N$. benthamiana to prevent infection and colonization by $P$. in- festans. We also produced a VIGS construct for phenylalanine ammonia lyase (NbPAL) because PAL is known to be involved in SA production by an alternative pathway, in which phenylalanine is converted to benzoic acid (BA) and, subsequently, BA is converted to SA (Mauch-Mani and Slusarenko 1996; Shah 2003). However, $N b P A L$-silenced plants showed resistance comparable with control plants, indicating that $N b P A L$ is dispensable for the age-related resistance of $N$. benthamiana (Supplementary Fig. 2).

To examine the effect of SA on susceptibility of young $N$. benthamiana, 25-day-old plants pretreated with acibenzolar- $S$ methyl (ASM), a functional analog of SA, at $100 \mathrm{ppm}$ were inoculated with $P$. infestans. Young plants pretreated with ASM showed complete resistance against $P$. infestans (Supplementary Fig. 3) (Vallad and Goodman 2004), suggesting that the lack of resistance in young $N$. benthamiana is a result of deficient induction of a SA-mediated signaling pathway.
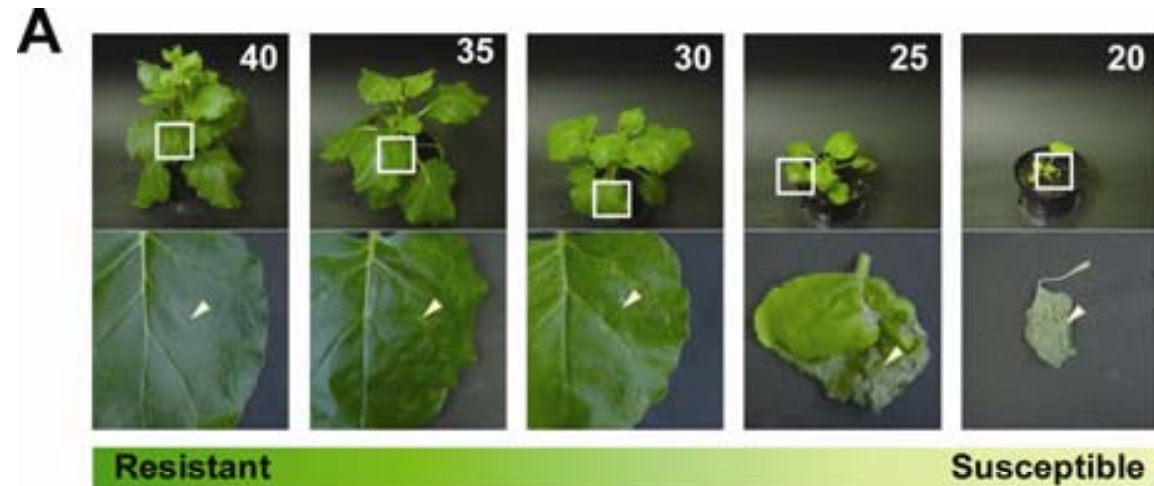

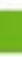
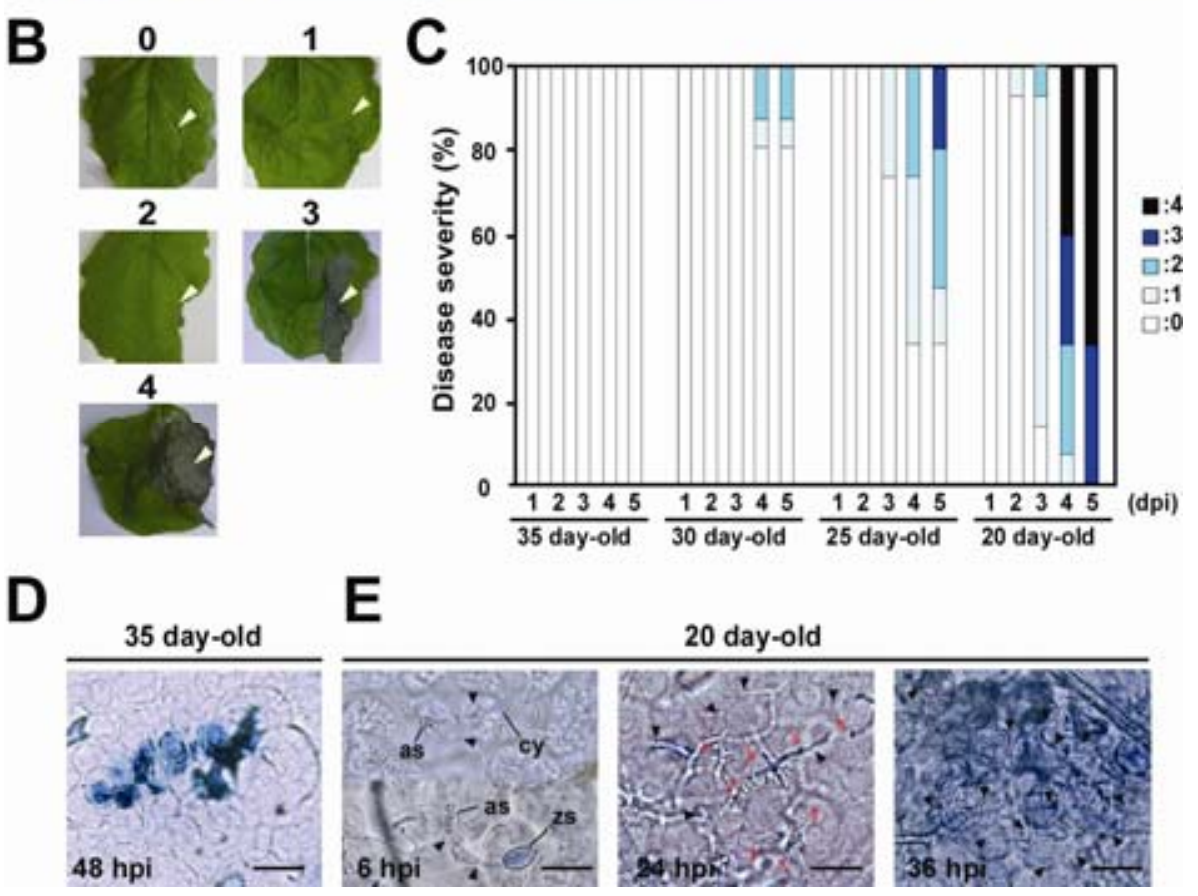

E

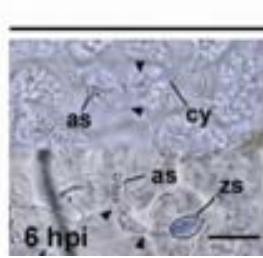

20 day-old
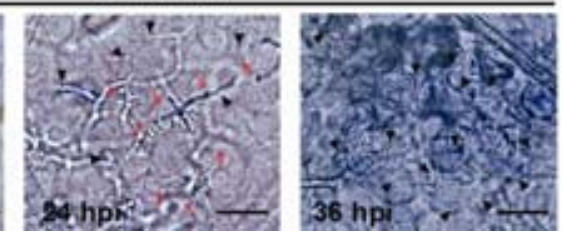

Fig. 1. Age-related resistance of Nicotiana benthamiana against Phytophthora infestans. A, $N$. benthamiana of different ages were tested for resistance to P. infestans isolate PI0-1. The numbers in each panel indicate the age of the plant in days from the date of sowing. Leaves of $N$. benthamiana were inoculated with a suspension of $P$. infestans zoospores at a concentration of $2 \times 10^{5}$ zoospore/ml and development of disease symptoms was evaluated. Results shown are representative of three separate experiments. Photographs of whole plants (top panels) and inoculated leaves (bottom panels) were taken 9 days after the inoculation. Arrowheads indicate the point of inoculation. B, Appearance of disease symptom showing differences in severity representative of the five classifications used in C. C, Plots showing percentages of $N$. benthamiana leaves with disease symptom severities in each of the five classes represented in B. Leaves of $N$. benthamiana of different ages were inoculated with $P$. infestans and severities of disease symptom were evaluated from 1 to 5 days after inoculation. At least 15 inoculated leaves from each plant of different ages were counted. D and E, Microscopic observation of mature (D) and young (E) $N$. benthamiana leaves after inoculation with $P$. infestans. Inoculated leaves were stained with lactophenol trypan blue to visualize dead plant cells and the hyphae of $P$. infestans. Black arrowheads and red arrows indicate the hyphae and haustoria of $P$. infestans, respectively; hpi, hours post inoculation; cy, cyst; as, appressorium-like swelling. Bars $=50 \mu \mathrm{m}$. 
NbICS1-silenced $N$. benthamiana showed enhanced cell death in response to the treatment of INF1 and NPP1.1.

$P$. infestans produces a large number of secretory proteins during the process of infection, including intracellular effectors (e.g., RXLR effectors) (Oh et al. 2009) and apoplastic elicitors (e.g., INF1 and NPP1.1) (Kamoun et al. 1997, Fellbrich et al. 2002). INF1, a major secretory protein of $P$. infestans, is thought to be a sterol carrier, which enables the pathogen to uptake sterol from the host plant, and it is also considered to act as a semi-PAMP in oomycete pathogens recognized by a limited number of dicot plants, including Nicotiana spp.
(Kamoun et al. 1993; Blein et al. 2002; Takemoto et al. 2005). A previous report suggested that INF1 is a virulence factor in interaction between $P$. infestans and $N$. benthamiana (Kamoun et al. 1998). NPP1.1 is a member of the Nep1-like proteins (NLP), which induce nonspecific cell death in dicot plants, although the function of NPP1.1 is unknown (Kanneganti et al. 2006). Biological function of NPP1.1 is unknown. It was reported that INF1 and NPP1.1 induce the death of plant cells through distinct mechanisms (Kanneganti et al. 2006). We employed INF1 and NPP1.1 to examine the effect of gene silencing on the induction of plant cell death. We constructed chi-
A

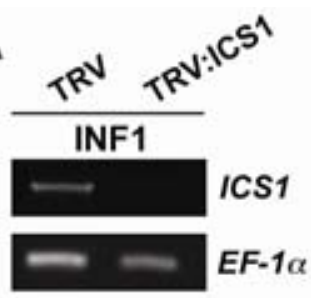

B

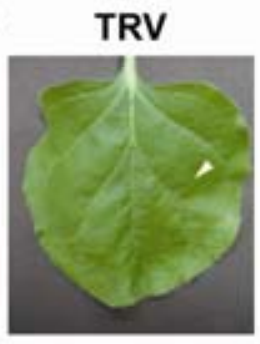

C

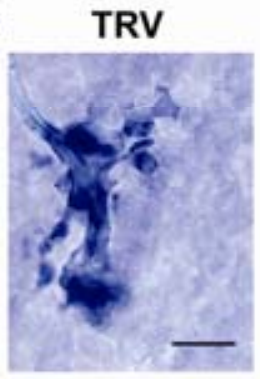

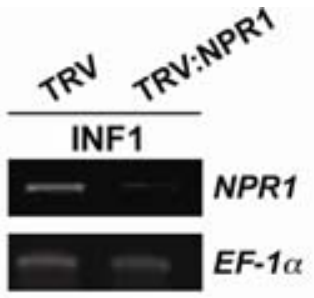
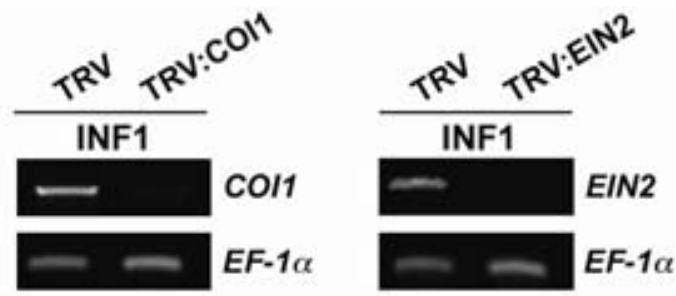

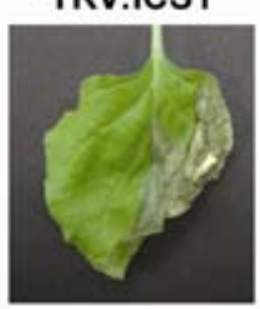

TRV:ICS1

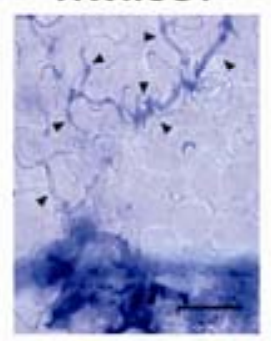

TRV:NPR1

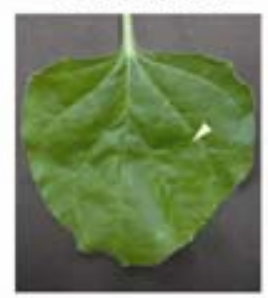

TRV:NPR1

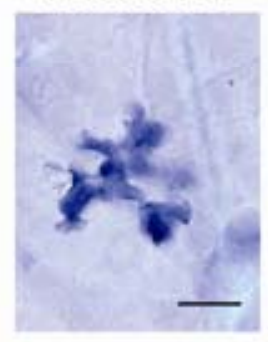

TRV:COI1

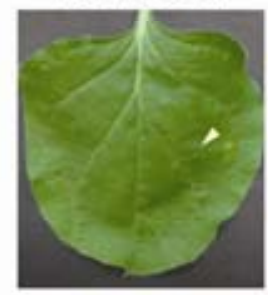

TRV:COI1

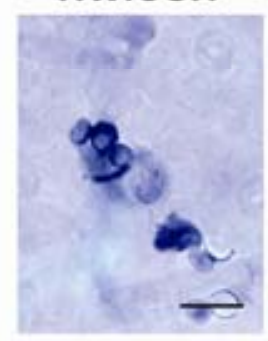

TRV:EIN2

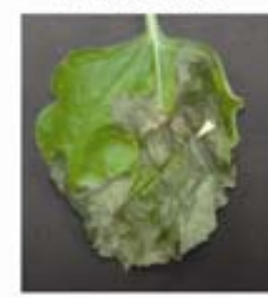

TRV:EIN2

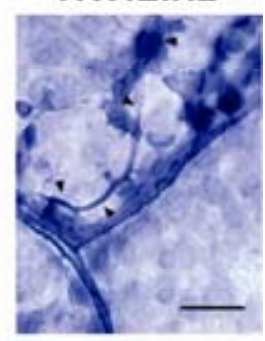

D

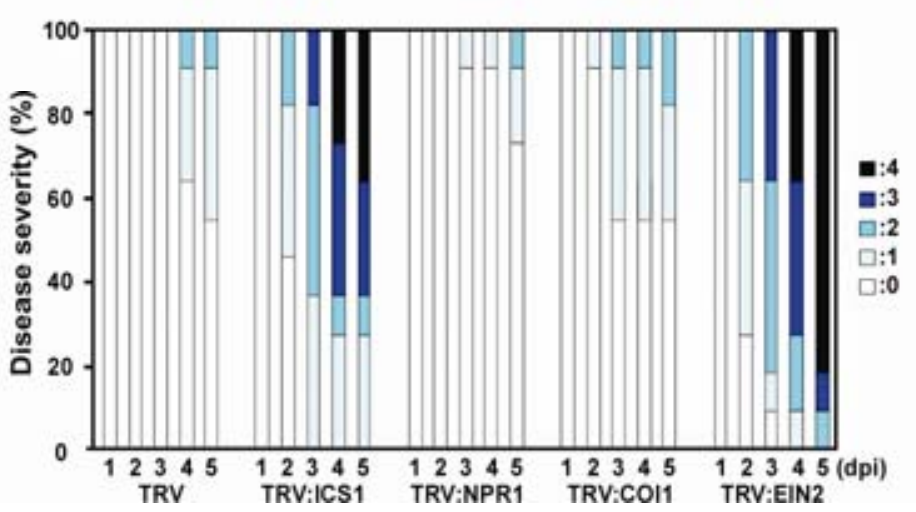

Fig. 2. Both NbICS1 and NbEIN2 are essential for age-related resistance of Nicotiana benthamiana to Phytophthora infestans. A, N. benthamiana was inoculated with Tobacco rattle virus (TRV), TRV:ICS1, TRV:NPR1, TRV:COI1, or TRV:EIN2, and total RNA was isolated from $N$. benthamiana leaves $12 \mathrm{~h}$ after the treatment with $150 \mathrm{nM}$ INF1. Silencing of target genes was confirmed by reverse-transcription polymerase chain reaction with gene-specific primers at least five separate leaves. B, Leaves of NbICS1-, NbNPR1-, NbCOI1-, or NbEIN2-silenced N. benthamiana were inoculated with P. infestans PI0-1. Arrowheads indicate the point of inoculation. Photographs were taken 9 days after inoculation. C, Microscopic observation of $N$. benthamiana leaves $48 \mathrm{~h}$ after inoculation with $P$. infestans. Inoculated leaves were stained with lactophenol trypan blue to visualize dead plant cells and the hyphae of $P$. infestans. Arrowheads indicate the hyphae of $P$. infestans. Bars $=50 \mu \mathrm{m}$. Similar results were obtained form at least 12 inoculated leaves. D, Plots showing percentages of $N$. benthamiana leaves with disease symptom severities in each of five classes. Leaves of NbICS1-, NbNPR1-, NbCOI1-, or NbEIN2-silenced plants were inoculated with P. infestans and severities of disease symptom were evaluated from 1 to 5 days after inoculation. At least 16 inoculated leaves from each silenced plant were counted. 
meric transgenes for mature INF1 or NPP1.1 with the signal peptide (sp) of tobacco PR1a (Cornelissen et al. 1987) fused to the $\mathrm{N}$ terminus and with hemagglutinin (HA)/StrpII tags at the $\mathrm{C}$ terminus. This allowed for both the expression of mature elicitor proteins in the intercellular spaces of transformed plant tissue and the detection of expressed proteins. The INF1 or NPP1.1 constructs were expressed transiently under the con-

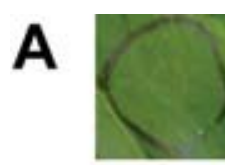

0

C

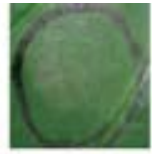

1

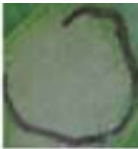

2

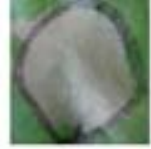

3
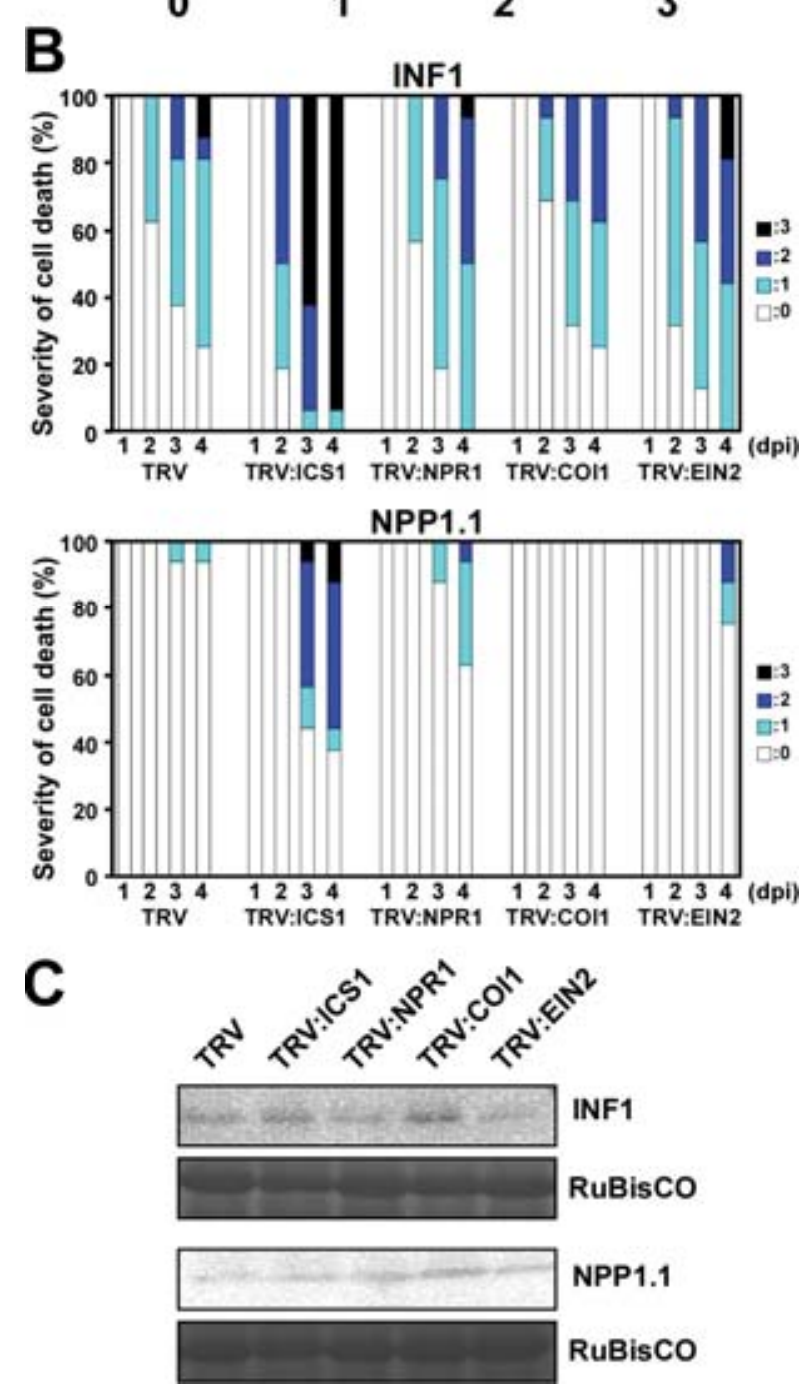

Fig. 3. NbICS1-silenced Nicotiana benthamiana showed enhanced induction of cell death after the expression of either INF1 or NPP1.1. A, Appearance of cell death showing differences in severity representative of the four classifications used in B. B, INF1:HA (hemagglutinin) (top) or NPP1:HA (bottom) were expressed by agroinfiltration in NbICS1-, NbNPR1-, NbCOI1-, or NbEIN2-silenced or control N. benthamiana. Plots show the severity of cell death among the $N$. benthamiana leaves and the percentages in each of the four classes represented in A. Leaves of NbICS1-, NbNPR1-, NbCOI1-, or NbEIN2-silenced or control plants were inoculated with Agrobacterium tumefactions with INF1:HA (top) or NPP1:HA (bottom) and severities of cell death were evaluated from 1 to 4 days after inoculation. At least 30 inoculated leaves from each silenced plants were counted. C, Protein samples were extracted from leaves of NbICS1-, NbNPR1-, NbCOI1-, or NbEIN2-silenced plants and control plants $48 \mathrm{~h}$ after inoculation with A. tumefaciens with INF1:HA (top) or NPP1:HA (bottom). Expressed HA-tagged proteins were detected by immunoblot analysis with anti-HA antibody. Results shown are representative of at least three separate experiments. trol of the Cauliflower mosaic virus (CaMV) 35S promoter by agroinfiltration into leaves of $N$. benthamiana. Cells of $N$. benthamiana leaves showed visible HR-like cell death induced by the expression of INF1, whereas there was no visible cell death after agroinfiltration with the vector alone (data not shown). Expression of NPP1.1 in the apoplastic space of $N$. benthamiana leaves also induced cell death, although cell death induced by NPP1.1 is considerably weaker compared with INF1-induced cell death (Fig. 3B). INF1 was expressed in leaves of NbICS1-, NbNPR1-, NbCOI1-, or NbEIN2silenced plants and induction of cell death was scored until 5 days after the inoculation with Agrobacterium tumefaciens carrying the INF1 vector. $N b N P R 1, N b C O I 1$, and $N b E I N 2$ plants showed no significant difference in the induction of cell death compared with the TRV-infected control plant, whereas NbICS1-silenced plants showed accelerated induction of cell death (Fig. 3B). Similarly, expression of NPP1.1 in ICS1silenced plants induced significantly more severe cell death (Fig. 3B). Immunoblot analysis was performed using anti-HA antibody to exclude the possibility that enhanced cell death in NbICSI-silenced plants was the result of increased accumulation of INF1 and NPP1.1 proteins. There were similar levels of the INF1 and NPP1.1 proteins in all gene-silenced and control plants (Fig. 3C); thus, it was confirmed that NbICS1silenced plant showed enhanced induction of cell death.

\section{Silencing of either NbICS1 or NbEIN2 compromised INF1-induced $\mathrm{O}_{2}^{-}$production in $N$. benthamiana.}

Production of ROS is a hallmark of plant defense responses and it is thought to control the degree of HR during the induction of disease resistance (Doke 1983; Torres and Dangl 2005).
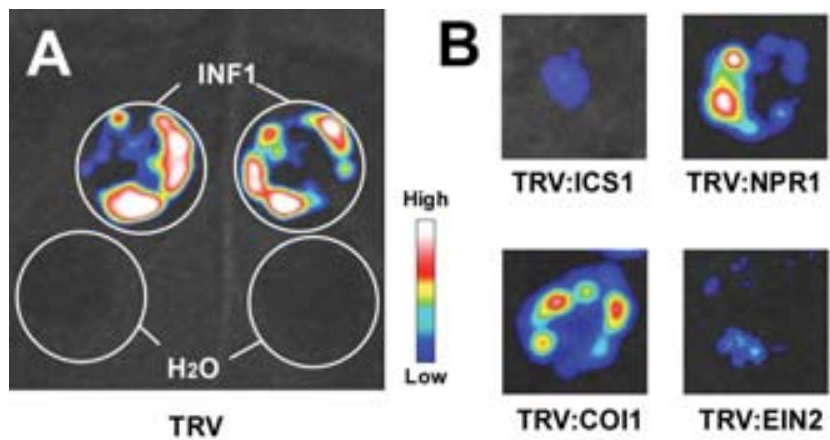

TRV:NPR1

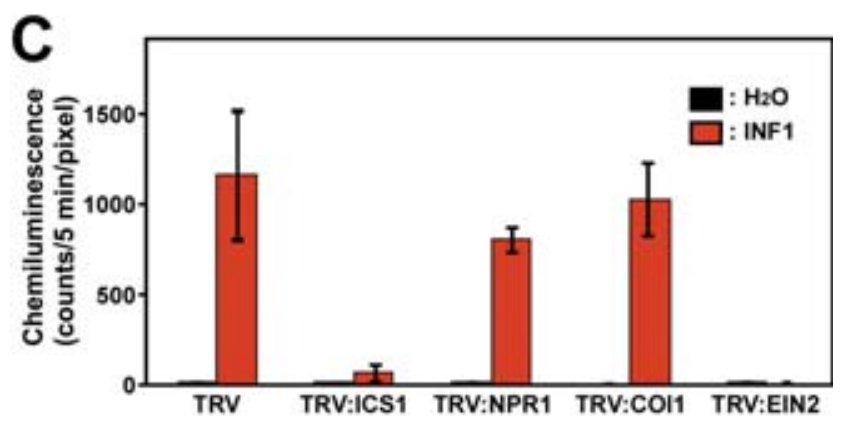

Fig. 4. Effects of silencing of NbICS1, NbNPR1, NbCOI1, or NbEIN2 genes on the $\mathrm{O}_{2}^{-}$production induced by treatment with INF1. A, Leaves of Tobacco rattle virus (TRV)-infected control Nicotiana benthamiana was

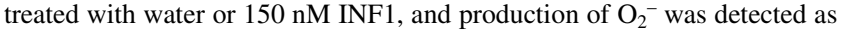
L-012 mediated chemiluminescence $12 \mathrm{~h}$ after treatment. Chemiluminescence images shown were obtained using a CCD camera. Circles indicate the area of water or INF1 treatment. B, Leaves of gene-silenced $N$. benthamiana were treated with $150 \mathrm{nM}$ INF1 and production of $\mathrm{O}_{2}^{-}$was detected as L-012 mediated chemiluminescence $12 \mathrm{~h}$ after treatment. C, Chemiluminescence intensities were quantified with a photon image processor. Data are means \pm standard error from four separate experiments. 
It has been reported that $N$. benthamiana produced ROS within $12 \mathrm{~h}$ after treatment with INF1 (Uruma et al. 2009). To investigate the effect of gene silencing on ROS production induced by INF1, NbICS1-, NbNPR1-, NbCOI1-, and NbEIN2-silenced $N$. benthamiana leaves were infiltrated with INF1, and production of $\operatorname{ROS}\left(\mathrm{O}_{2}^{-}\right)$was measured as the chemiluminescence using the luminol derivative L-012 (Nishinaka et al. 1993; Asai et al. 2008). At $12 \mathrm{~h}$ after treatment with INF1, NbNPRI- and $\mathrm{NbCOI1-silenced} N$. benthamiana showed a level of ROS production similar to the control plant, whereas NbICS1- and NbEIN2-silenced $N$. benthamiana showed significant reduction of ROS production (Fig. 4A and B). Given that ROS production was reported to positively regulate the HR in disease resistance (Torres et al. 2002; Yoshioka et al. 2003; Pogány et al. 2009), NbICS1-silenced plants, which showed enhanced induction of cell death (Fig. 3), were expected to produce ROS rapidly in response to elicitor treatment. However, substantial production of ROS was not detected at 1,3 , or $6 \mathrm{~h}$ after INF1 treatment (data not shown); therefore, it is concluded that elicitor-induced ROS production was compromised in NbICS1-silenced plants. Together, these results indicated that both SAand ET-mediated signaling pathways are necessary for the induction of INF1-induced ROS production in N. benthamiana.

\section{Expression of defense-related genes}

in ICS1- and EIN2-silenced plants.

The effect of gene silencing of NbICS1 or NbEIN2 on the expression of various defense-related genes was investigated. Expression of $P R-1 a$, a marker gene of disease resistance, is suppressed in NbICS1-silenced plant (Fig. 5), indicating that $N b P R-1 a$ is SA regulated, consistent with previous reports (Vlot et al. 2009). Vacuolar processing enzymes (VPE) were originally identified as enzymes involved in maturation of seed storage proteins (Hara-Nishimura et al. 1991). Recent reports also indicated that these enzymes have caspase activity required for the induction of the HR during the interaction between Tobacco mosaic virus (TMV) and tobacco plants with the corresponding resistance gene $N$ (Hatsugai et al. 2004). Expression of $N b V P E$ was significantly reduced in NbICS1-silenced plants (Fig. 5). 5-Epi-aristolochene synthase (EAS) is an enzyme for the biosynthesis of capsidiol, a major phytoalexin of Nicotiana and Capsicum spp. (Bailey et al. 1975). INF1-induced expression of $N b E A S$ was repressed by gene silencing of NbEIN2 (Fig. 5). Silencing of either NbICS1 or NbEIN2 had no effect on expression of marker gene $h s r 203 J$, which is specifically expressed in HR-induced cells (Pontier et al. 1998). Expression of $N b R b o h B$, a gene for the respiratory-burst oxidase homolog (rboh) involved in ROS production during disease resistance (Asai et al. 2008; Yoshioka et al. 2003), was induced by INF treatment but not affected by silencing of either NbICS1 or NbEIN2, although ROS production by these silenced plants was considerably reduced (Fig. 4). Therefore, it is suggested that regulation of ROS production by SA and ET signaling is post transcriptional.

\section{Neither SA-regulated NbPR-1a nor NbVPE genes are involved in $N$. benthamiana resistance against $P$. infestans.}

To investigate the role of SA-regulated genes in $N$. benthamiana resistance against $P$. infestans, NbVPE- and NbPR-lasilenced $N$. benthamiana were inoculated with $P$. infestans (Supplementary Fig. 4). Over 10 days of observation after the inoculation, $N b V P E$ - and $N b P R$-la-silenced plants did not show any development of disease symptoms. Although the construct for silencing of $N b V P E$ is designed to suppress the expression of two VPE genes, NbVPE-1a and $-1 b$, which are reported to be involved in the $N$-gene-dependent cell death in- duced by TMV (Hatsugai et al. 2004), NbVPE-silenced plants showed comparable induction of cell death after the treatment of INF1 to control plant (data not shown). Our data indicated that neither $N b P R-1 a$ nor the $N b V P E$ genes are essential for $N$. benthamiana resistance against $P$. infestans.

Expression of genes for capsidiol biosynthesis, $\mathrm{NbEAS}$, and $\mathrm{NbEAH}$, are regulated by ET and essential for the resistance to $P$. infestans.

Nicotiana and Capsicum spp. produce a sesquiterpenoid phytoalexin, capsidiol, as a pathogen- and elicitor-inducible defense metabolite (Bailey et al. 1975). Formation of capsidiol involves the cyclization of farnesyl pyrophosphate (FPP) to the sesquiterpenoid hydrocarbon 5-epi-aristolochene catalyzed by EAS (Facchini and Chappell 1992) and two subsequent hydroxylation steps by 5-epi-aristolochene dihydroxylase (EAH) (Ralston et al. 2001). Given that INF1-induced expression of $N b E A S$ was suppressed in EIN2-silenced $N$. benthamiana, it is expected that the induction of $N b E A S$ expression is regulated by ET. We examined expression of $N b E A S$ in $N$. benthamiana exposed to exogenous ET. At $6 \mathrm{~h}$ after the treatment, expression of $N b E A S$ was significantly induced by treatment of ET at $100 \mathrm{ppm}$, consistent with suppressed expression of $N b E A S$ in EIN2-silenced plants (Fig. 6A). Similarly, expression of $\mathrm{NbEAH}$ was also found to be induced by ET treatment (Fig. 6A). $N b E A S$ - and $N b E A H$-silenced plants were produced to examine the role of capsidiol in age-related resistance of $N$. benthamiana to $P$. infestans. Within 5 days after the inoculation of $P$. infestans, $N b E A S$ - and $N b E A H$-silenced plants showed severe disease symptoms, which were comparable with those of NbEIN2-silenced plants (Fig. 6C and E). Microscopic observation with lacto phenol trypan blue staining revealed extensive colonization by $P$. infestans (Fig. 6D). Remarkably, plant cells surrounding the extending hyphae of $P$. infestans were often well stained by trypan blue or collapsed, indicating that cells of $N b E A S$ - or $N b E A H$-silenced plants were capable

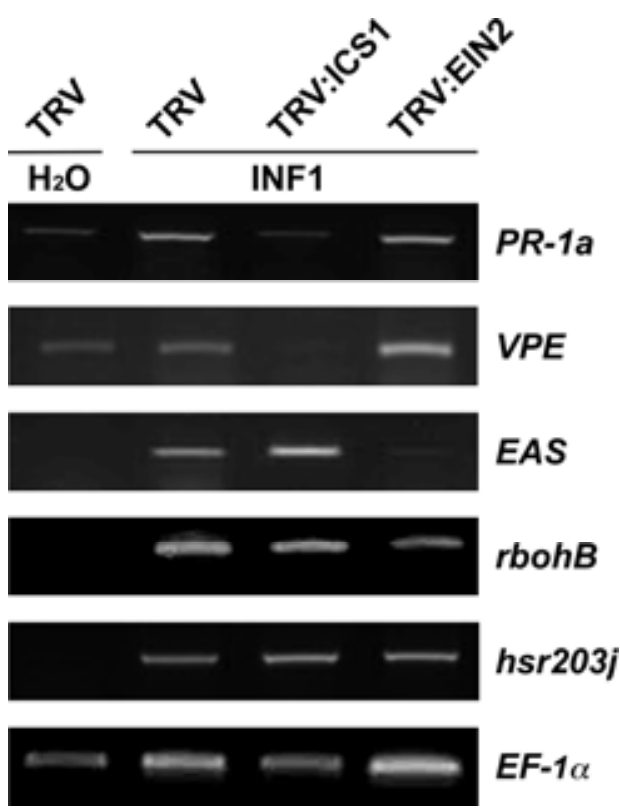

Fig. 5. Expression of defense-related genes in NbICS1- or NbEIN2silenced Nicotiana benthamiana. Total RNA was isolated from NbICS1-or NbEIN2-silenced or control $N$. benthamiana $12 \mathrm{~h}$ after treatment with water $\left(\mathrm{H}_{2} \mathrm{O}\right)$ or $150 \mathrm{nM}$ INF1 (INF1). Reverse-transcription polymerase chain reaction was performed with primers specific for $N b P R-1 a, N b V P E$, $N b E A S, N b r b o h B$, and Nbhsr203J. Constitutively expressing $N b E F-1 \alpha$ was used as an internal standard. Results shown are representative of at least five separate experiments. 
of inducing HR-like cell death in response to the contact with $P$. infestans hyphae (Fig. 6D). Consistently, induction of cell death and production of ROS induced by INF1 in NbEAS- or

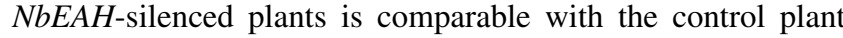
(Supplementary Fig. 5). These results indicated that a major consequence of activation of the ET signaling pathway in response to an attack by $P$. infestans is capsidiol production, which plays a crucial role for preventing the extension of $P$. infestans in mature N. benthamiana plants (Supplementary Fig. 6).

\section{DISCUSSION}

$\boldsymbol{N}$. benthamiana has "adult resistance" against $\boldsymbol{P}$. infestans.

Previously, it was not clear whether $N$. benthamiana was resistant against $P$. infestans because of contradictory reports about their interaction. (Kamoun et al. 1998; Yoshioka et al. 2003; Becktell et al. 2006; Asai et al. 2008). In this study, we revealed that mature plants of $N$. benthamiana show robust resistance against $P$. infestans, whereas relatively young plants are always susceptible to this pathogen (Fig. 1). This agerelated resistance or "adult resistance" has been found in some plant-microbe interactions (Panter and Jones 2002; DeveleyRivière and Galiana 2007). In tobacco, increased resistance against $P$. parasitica and TMV has been observed in the flowering stage (Yalpani et al. 1991; Hugot et al. 1999). In Arabidopsis, age-related resistance to bacterial pathogen Pseudomonas syringae pv. tomato and oomycete pathogen $H$. arabidopsidis correlated with the transition to flowering. However, the same resistance was not effective for necrotrophic bacterial (Erwinia carotovora) and fungal (Botrytis cinerea) pathogens and biotrophic fungal pathogen Erysiphe cichoracearum (Rusterucci et al. 2005).

McDowell and associates (2005) reported that H. arabidopsidis isolate Emco5 displayed full virulence on cotyledons of Arabidopsis ecotype Col-0 but induced weak resistance reactions in true leaves, which were conditional on a single locus
A
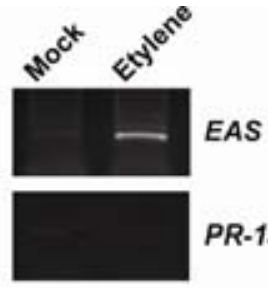

PR-1a

B

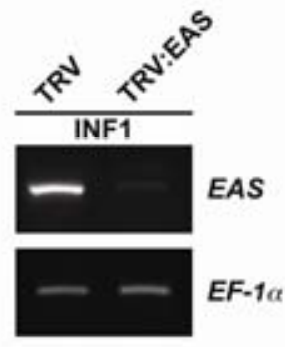

C

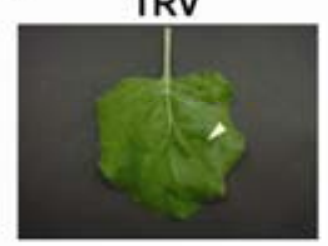

TRV:EAH

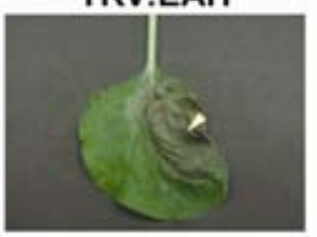

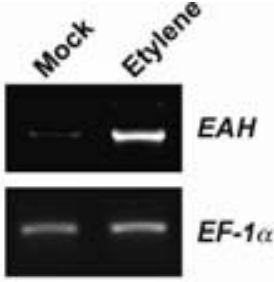
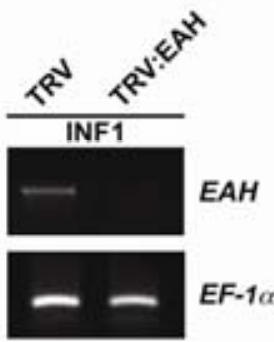

D

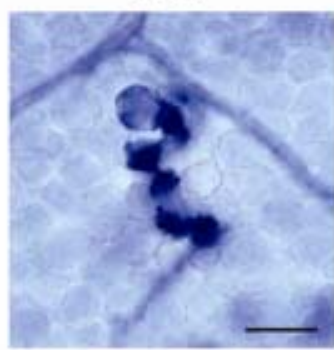

TRV:EAH

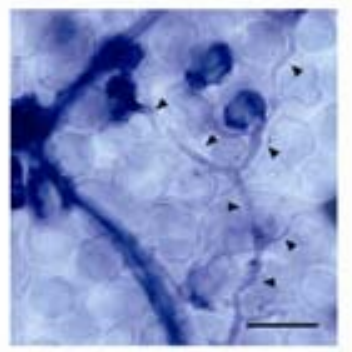

TRV:EAS

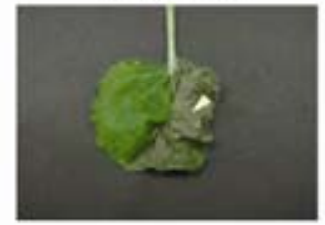

TRV:EIN2

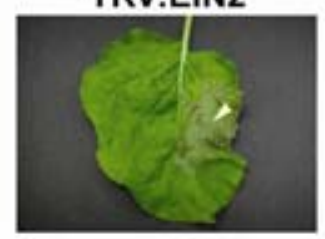

TRV

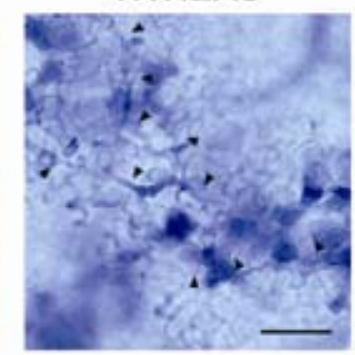

TRV:EIN2
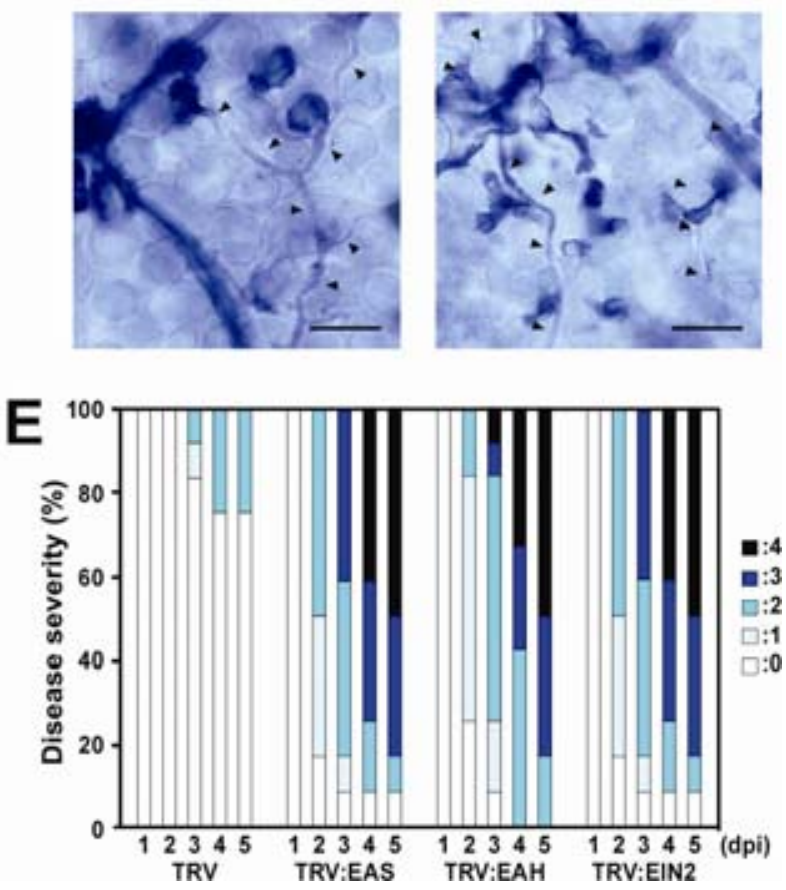

Fig. 6. Expression of capsidiol biosynthesis genes, $N b E A S$ and $N b E A H$, is regulated by ethylene and is essential for the resistance of Nicotiana benthamiana against Phytophthora infestans. EAS = 5-epi-aristolochene synthase and EAH = 5-epi-aristolochene dihydroxylase. A, $N$. benthamiana plants were incubated with ethylene at $100 \mathrm{ppm}$ for $6 \mathrm{~h}$ and expression of $N b E A S$ and $N b E A H$ was detected by reverse-transcription polymerase chain reaction (RT-PCR) using gene-specific primers. Control plants (mock) were incubated under identical conditions in the absence of added ethylene. B, $N$. benthamiana was inoculated with Tobacco rattle virus (TRV), TRV:EAS, or TRV:EAH and total RNA was isolated from $N$. benthamiana leaves $12 \mathrm{~h}$ after treatment with $150 \mathrm{nM}$ INF1. Expression of $N b E A S$ and $N b E A H$ were detected by RT-PCR using gene-specific primers. C, Leaves of $N b E A S$ - and $N b E A H$-silenced $N$. benthamiana were inoculated with $P$. infestans and photographs were taken 9 days after inoculation. Arrowheads indicate the point of inoculation. D, Microscopic observation of $N$. benthamiana leaves $48 \mathrm{~h}$ after inoculation with $P$. infestans. Inoculated leaves were stained with lactophenol trypan blue to visualize dead plant cells and the hyphae of $P$. infestans. Arrowheads indicate the hyphae of $P$. infestans. Bars $=50 \mu \mathrm{m}$. Similar results were obtained form at least 12 inoculated leaves. E, Plots showing the severity of disease symptoms as percentages in each of five classes of $N$. benthamiana. Leaves of $N b E A S$-, $N b E A H$-, or NbEIN2-silenced or control plants were inoculated with P. infestans and severities of disease symptom were evaluated from 1 to 5 days after inoculation. At least 12 inoculated leaves from each silenced plant were counted. 
$R P P 31$. In interactions between tomato and leaf mold pathogen Cladosporium fulvum, both tomato $C f-9$ and $C f-9 B$ conferred resistance to $C$. fulvum with an avirulence gene in mature plants, whereas only $C f-9$ was effective for seedling resistance (Panter et al. 2002). In rice, Xa21-dependent resistance against the bacterial pathogen Xanthomonas oryzae pv. oryzae progressively increases from the susceptible two-leaf stage through to the resistant nine- to ten-leaf stage (Century et al. 1999). These reports indicated that, at least in some interactions, mechanisms similar to $\mathrm{R}$ protein-mediated recognition of pathogens is involved in age-related resistance. In interactions between $N$. benthamiana and Phytophthora infestans, the primary candidate for the $P$. infestans avirulence factor is secretory protein INF1, because a previous report indicated that $P$. infestans with suppressed expression of the infl gene became more pathogenic to $N$. benthamiana (Kamoun et al. 1998). However, another report indicated that expression of the infl gene was subtle in the biotrophic phase of infection, probably to avoid the recognition by the host plant, but then upregulated in the necrotrophic phase of infection, most likely for uptake of sterol from the plant plasma membrane (Kamoun et al. 1997; Blein et al. 2002). Therefore, we cannot rule out the possibility that a factor other than INF1 is the primary factor in the induction of age-related resistance of $N$. benthamiana to $P$. infestans.

\section{Penetration resistance would be a part of $N$. benthamiana resistance against $P$. infestans.}

The Arabidopsis pen 2 mutant has impaired penetration resistance against nonpathogenic powdery mildew Blumeria graminis f. sp. hordei. This mutant also showed reduced penetration resistance against $P$. infestans with increased incidence of hypersensitive cell death, indicating that penetration resistance is backed up by an HR-dependent defense mechanism (Lipka et al. 2005). The pen 2 mutant, unlike the wild-type plant, developed visible necrosis after inoculation with $P$. infestans, and trypan blue staining revealed an increased number of dead cells (Westphal et al. 2008). In interactions between mature $N$. benthamiana and $P$. infestans, microscopic observation with trypan blue staining revealed the induction of a few HR in epidermal and mesophyll cells of $N$. benthamiana but infection by the majority of the zoospores inoculated ceased at the surface of plant leaves without induction of cell death. This is in contrast to the macroscopically visible necrotic lesions on potato leaves inoculated with avirulent $P$. infestans (Kitazawa and Tomiyama 1969; Ballvora et al. 2002). Our observations indicate that penetration resistance is a basal resistance mechanism of $N$. benthamiana against $P$. infestans.

\section{SA signaling but not NPR1 is involved in age-related resistance of $N$. benthamiana against $P$. infestans.}

Several previous reports indicated that age-related resistance in various but not all plant-pathogen interactions is dependent on production of SA (Develey-Rivière and Galiana 2007). In this study, young and susceptible $N$. benthamiana plants showed resistance to $P$. infestans after pretreatment with a functional analog of SA, ASM. This suggested that a lack of resistance in young $N$. benthamiana is a result of failure in induction of the SA-mediated signaling pathway. Moreover, silencing of the NbICS1 gene compromised resistance of mature plants against $P$. infestans, confirming the importance of SA signaling in age-related resistance of $N$. benthamiana against $P$. infestans.

NPR1 is a central factor of SA signaling in disease resistance, which regulates the expression of various SA-regulated genes, including a marker gene for induction of disease resis- tance, PR-la (Shah 2003; Pieterse and van Loon 2004). Although $N b N P R 1$ was reported as a gene required for $N$-genedependent resistance against TMV in $N$. benthamiana (Liu et al. 2002), this gene was not required for age-related resistance against $P$. infestans (Fig. 2). Two genes regulated by SA signaling, $N b P R-1 a$ and $N b V P E$, were not required for the resistance of $N$. benthamiana against $P$. infestans. Rivière and associates (2008) reported that silencing of the PRl gene in $N$. tabacum had no impact on age-related resistance against $P$. parasitica, which is consistent with our result. NbVPE was reported to be required for the induction of $\mathrm{N}$-gene-dependent HR (Hatsugai et al. 2004). These previous reports and our data indicate that, although resistance against both $P$. infestans and TMV requires activation of a SA signaling pathway, there are different sets of SA-regulated mechanisms directly involved in resistance against these pathogens.

\section{SA synthesis regulated by ICS1 but not by PAL is essential for the resistance of $N$. benthamiana against $P$. infestans.}

There are two known pathways for SA biosynthesis in plants. SA synthesis from phenylalanine via trans-cinnamic acid and benzoic acid has been reported in various plant species, including tobacco and Arabidopsis (Mauch-Mani and Slusarenko 1996; Ribnicky et al. 1998). Relatively recently, an alternative pathway for SA production from chorismate via isochorismate was found in plants (Wildermuth et al. 2001). This pathway was originally identified in bacteria (Serino et al. 1995). In interactions between TMV and tobacco, PAL and benzoic acid 2-hydroxylase (BA2H) activity is induced by inoculation with the pathogen (León et al. 1993; Bate et al. 1994). Moreover, accumulation of SA was reduced in transgenic tobacco with suppressed expression of the $P A L$ gene (Pallas et al. 1996). These reports suggest that SA is primarily synthesized via the pathway involving PAL and BA2H for TMV resistance in tobacco. However, there is no report in Arabidopsis about the involvement of PAL in disease resistance despite screening extensively for mutants which show reduced disease resistance with various pathogens (Thatcher et al. 2005). Therefore, it is most likely that PAL is not a major factor in disease resistance in Arabidopsis. In contrast, Arabidopsis mutant sid2 has a disrupted ICS1 gene and shows reduced resistance to various pathogens, including $H$. arabidopsidis and Pseudomonas syringae. This indicates that ICS1-mediated SA biosynthesis is central to the disease resistance of Arabidopsis against some pathogens (Glazebrook 2005; Vlot et al. 2009). For SA biosynthesis in response to ozone $\left(\mathrm{O}_{3}\right)$ exposure, SA is produced by a PAL-mediated pathway in N. tabacum, whereas Arabidopsis produces SA via isochorismate (Ogawa et al. 2005). This report indicated that the pathway for SA production is variable between species, even during a response to the same type of stress. In this study, we revealed that NbICS1 but not $N b P A L$ is essential for the resistance of $N$. benthamiana against Phytophthora infestans (Fig. 2). Although expression of $N b P A L$ is induced by INF1 treatment, gene silencing of $N b P A L$ had no effect on resistance of $N$. benthamiana against $P$. infestans, suggesting that the ICS1-mediated pathway is the central biosynthetic pathway for SA in disease resistance of $N$. benthamiana. Consistently, Catinot and associates (2008) have reported that production of SA, induced by inoculation with a bacterial pathogen as well as exposure to UV light, is suppressed in NbICS1-silenced plants.

\section{Silencing of ICS1 enhanced cell death induced by INF1 and NPP1.1.}

NbICS1-silenced plants showed accelerated cell death by apoplastic expression of either INF1 or NPP1.1 (Fig. 3). It was reported that cell death induced by NPP1.1 is dependent on 
COI1, MEK2, NPR1, and TGA2.2 but silencing of these genes had no influence on cell death induced by INF1 (Kanneganti et al. 2006). Therefore, the extensive cell death response in NbICS1-silenced plants is probably the result of unsuccessful termination of cell death induced in neighboring cells. It is not clear whether this accelerated cell death is a cause of enhanced susceptibility in mature $N$. benthamiana; however, it is expected that accelerated cell death might facilitate the growth of $P$. infestans in the necrotrophic phase.

\section{The ET-mediated signaling pathway regulates the production of capsidiol in $N$. benthamiana.}

In this study, it was shown that ET is essential and sufficient to induce the expression of $N b E A S$ (Figs. 5 and 6). Consistent with our data, a recent report by Maldonado-Bonilla and associates (2008) indicated that the promoter region of the EAS gene from chili pepper (Capsicum annuum) and tobacco $(N$. tabacum) have an ET-responsive element (GCCGCC). Given that expression of $\mathrm{NbEAH}$ is also regulated by ET, then the production of capsidiol in $N$. benthamiana is primarily regulated by the ET-mediated signal transduction pathway. Previous circumstantial evidence also indicated a possible link between production of ET and capsidiol in tobacco suspension cells treated with the elicitor protein cryptogein from P. cryptogea (Milat et al. 1991). Our report shows the first clear evidence indicating that production of capsidiol in Nicotiana spp. is directly regulated by ET and involved in disease resistance. Phytoalexins from different plant species are chemically diverse, including terpenoids, glycosteroids, and alkaloids, and the phytoalexins are produced by distinctive pathways (Hammerschmidt 1999). Indolic alkaloid phytoalexin of Arabidopsis, camalexin, does not contribute to resistance to the biotrophic oomycete $H$. arabidopsidis (Glazebrook et al. 1997) and fungus E. orontii (Reuber et al. 1998), whereas this phytoalexin is essential for resistance against the necrotrophic fungal pathogens Alternaria brassicicola (Thomma et al. 1999) and Botrytis cinerea (Ferrari et al. 2003). ET signaling is not substantially involved in production of camalexin in Arabidopsis because mutation in ein2 did not compromise resistance against $A$. brassicicola and $B$. cinerea (Thomma et al. 1999; Ferrari et al. 2003).

\section{Regulation and role of ROS production}

in the interaction between $N$. benthamiana and $P$. infestans.

Rapid production of ROS is one of the earliest reactions during the induction of plant disease resistance (Doke et al. 1996; Torres and Dangle 2005). Rbohs from different plant species have been identified as essential enzymes for the induction of ROS in disease resistance (Simon-Plas et al. 2002; Torres et al. 2002; Yoshioka et al. 2003). Production of ROS in an Arabidopsis rbohD/rbohF double mutant was significantly reduced in response to inoculation with avirulent bacterial and oomycete pathogens (Torres et al. 2002). Similarly, VIGS of NbRbohA and $N b R b o h B$, orthologs of Arabidopsis rbohD and rbohF, in $N$. benthamiana compromised ROS accumulation during a $P$. infestans infection (Yoshioka et al. 2003). Lherminier and associates (2009) reported that $N$. tabacum transformed with antisense $N t R b o h D$ showed reduced ROS production in response to the elicitor protein, cryptogein. In this study, significant reduction of elicitor-induced ROS production in NbICS1and NbEIN2-silenced $N$. benthamiana was observed (Fig. 4). Given the expression level of the gene for NbRbohB, a NADPH oxidase for ROS production in disease resistance (Asai et al. 2008), is not altered when these silenced plants are treated with INF1 (Fig. 5), and regulation of ROS production by either SA or ET is probably posttranscriptional. There are some reports showing that application of SA can promote ROS production, whereas others show that ROS production could enhance SA accumulation (Overmyer et al. 2003). Based on these reports, it is proposed that production of SA and ROS form a selfamplifying loop. There are relatively few reports about regulation of ROS production by ET. In rice roots, adventitious root primordia are formed at the nodes of the stem during plant development, and root growth is preceded by death of epidermal cells that cover the root primordial. Emergence of the root is promoted by ET-induced ROS production followed by local death of epidermal cells, indicating that ET acts upstream of ROS in epidermal cell-death signaling (Steffens and Sauter 2009). In the interaction between Arabidopsis and A. brassicicola, application of aminoethoxyvinylglycine, an inhibitor of ET biosynthesis, reduced the RBOHD-dependent ROS generation (Pogány et al. 2009).

Although it is clear that particular isoforms of Rboh are involved in ROS production in plant disease resistance, knockout or knockdown of Rboh genes have contrasting effects in different plant-microbe interactions. Arabidopsis rbohD/rbohF mutants displayed reduced HR in response to inoculation with avirulent Pseudomonas syringae pv. tomato compared with the wild type but bacterial growth in the host plant was not affected (Torres et al. 2002). Moreover, in adult resistance of Arabidopsis Col-0 against $H$. arabidopsidis isolate Emco 5, rbohD/rbohF double mutants displayed enhanced induction of cell death and resistance (Torres et al. 2002). Pogány and associates (2009) reported that Arabidopsis RbohD has dual roles in cell-death induction in the Arabidopsis-Alternaria pathosystem. In this system, ROS produced by RbohD promotes cell death in the first cell directly attacked by the pathogen while also suppressing the spread of cell death to neighboring cells. Knockout of rbohD, however, had no impact on the infection of $A$. brassicicola. $N$. tabacum with antisense $\mathrm{NtRbohD}$ showed comparable resistance to the wild-type plant against Phytophthora parasitica (Lherminier et al. 2009). In contrast, Yoshioka and associates (2003) indicated that Potato virus $X$-mediated VIGS of either $N b R b o h A$ or $N b R b o h B$ partially compromised resistance of $N$. benthamiana to $P$. infestans. However, in our experimental conditions, TRV-mediated VIGS of $N b R b o h B$ had no obvious effect on the resistance of mature $N$. benthamiana to $P$. infestans, although we detected almost complete loss of ROS production induced by INF1 in the $N b R b o h B$-silenced plants (Y. Shibata and D. Takemoto, unpublished data). Therefore, although gene silencing of NbICS1 and NbEIN2 compromised both disease resistance and ROS production, we consider that ROS is unlikely to be directly involved in age-related resistance of $N$. benthamiana to $P$. infestans.

In summary, our data indicate that age-related resistance of $N$. benthamiana to $P$. infestans requires activation of both SAand ET-mediated signal transduction pathways. Microscopic observation revealed that penetration resistance is partially effective for $N$. benthamiana resistance against $P$. infestans. Although knockdown of either SA- or ET-mediated signaling compromised ROS production induced by an elicitor, we consider that production of ROS is not directly involved in disease resistance. We propose that $N$. benthamiana requires SA-regulated appropriate induction of hypersensitive cell death and ETregulated production of phytoalexin to prevent infection during both the biotrophic and necrotrophic phases of $P$. infestans.

\section{MATERIALS AND METHODS}

Biological materials, growth conditions, and inoculation.

$N$. benthamiana plants were grown in an environmentally controlled growth room at $23^{\circ} \mathrm{C}$ with $16 \mathrm{~h}$ of light per day. $P$. infestans isolates were either maintained on susceptible potato (S. tuberosum) tubers (isolates PI0-1 and PI1234-1) or on rye media (isolates NE0805, IG0803, MR0803, 08YB1, 08YD1, 
and $08 \mathrm{MB}$ ), at $20^{\circ} \mathrm{C}$. Collection of zoosporangia and induction of zoospore production from P. infestans PI0-1 or PI1234-1 was performed as described by Doke (1975). Zoosporangia suspensions from the remaining $P$. infestans isolates were prepared as follows. $P$. infestans isolates were subcultured on rye media for 7 to 10 days and $20 \mathrm{ml}$ of water was added to the surface of the $P$. infestans colonies, which were then rubbed with a cotton swab to release the zoosporangia. Induction of zoospores was performed as described previously (Doke 1975). Leaves of $N$. benthamiana were inoculated with a 1-ml aliquot of $P$. infestans zoospores $\left(2 \times 10^{5}\right.$ zoospores $\left./ \mathrm{ml}\right)$ and covered with lens paper to keep the suspension of zoospores on the surface of the leaves. The inoculated plants were kept at high humidity at $20^{\circ} \mathrm{C}$ for 1 day after the inoculation, then were moved to a growth room at $23^{\circ} \mathrm{C}$.

\section{Treatment of $N$. benthamiana with chemicals.}

Treatment with ASM was performed as follows. ASM (benzo $(1,2,3)$ thiadiazole-7-carbothioic acid $S$-methyl ester) (Vallad and Goodman 2004) at 100 ppm with 10\% (wt/vol) wettable powder was treated by soil drenching (approximately $40 \mathrm{ml}$ per $300 \mathrm{ml}$ of soil) 2 days before the inoculation of $P$. infestans. Control plants were treated with same amount of water with $10 \%$ (wt/vol) soluble powder. Treatment with ET was performed as follows. $N$. benthamiana plants (35 days old) were placed in a gas-tight acryl chamber. ET was introduced into the chamber at a final concentration of $100 \mathrm{ppm}$ and plants were incubated at $23^{\circ} \mathrm{C}$ for $6 \mathrm{~h}$. Control plants were incubated under identical conditions in the absence of added ET.

\section{Preparation and treatment of INF1 elicitor.}

Escherichia coli cells (DH5 $\alpha$ ) carrying a chimeric plasmid containing inf1, pFB53 (Kamoun et al. 1997), were cultured overnight at $37^{\circ} \mathrm{C}$, diluted $(1: 100)$ in Luria-Bertani (LB) medium with ampicillin at $50 \mu \mathrm{g} / \mathrm{ml}$, and grown until the optical density at $600 \mathrm{~nm}\left(\mathrm{OD}_{600}\right)$ of the culture reached 0.6. Production of INF1 was induced by adding $0.4 \mathrm{mM}$ isopropyl $\beta$-Dthiogalactopyranoside for 3 to $4 \mathrm{~h}$. The culture was centrifuged and the resultant supernatant was dialyzed against water with SnakeSkin dialysis tubing (7-kDa molecular mass cutoff; Pierce Biotechnology, Rockford, IL, U.S.A.) overnight at $4^{\circ} \mathrm{C}$.

\section{DNA sequencing and bioinformatics.}

DNA sequencing utilized the dideoxynucleotide chain termination method using Big-Dye (version 3) chemistry (Applied BioSystems, Foster City, CA, U.S.A.) and the separation of products on an ABI3130 analyzer (Applied BioSystems). Sequence data was analyzed and annotated in MacVector (version 10.6; MacVector Inc., Cary, NC, U.S.A.) or GENETYX (version 7; GENETYX Corp., Tokyo). Sequences of cDNA for NbICS1 (Catinot et al. 2008) (accession no. EU257505), NbCOII (Liu et al. 2004) (AY547493), and NbVPE1-a (Hatsugai et al. 2004) (AB181187) have been published. The sequence of cDNA for $N b E A S$ was obtained from the $N$. benthamiana expressed sequence tag (EST) database (PlantGDB, Sequence ID; PUT173a-Nicotiana_benthamiana-17394) by searching with the sequence of $N$. tabacum EAS (Wu et al. 2005) (AY313939). The sequence of cDNA for NbEIN2 was obtained from the EST database (PUT-173a-Nicotiana_benthamiana-110727) by searching with the sequence of Arabidopsis thaliana EIN2 (Alonso et al. 1999) (AAD41076). Partial cDNAs for NbNPRl, NbPAL, NbPRla, Nbhsr203j, and NbEAH were amplified from $N$. benthamiana cDNA with specific primers designed from $N$. tabacum sequences for NPRl (Liu et al. 2002) (AF480488), PAL1 (Nagai et al. 1994) (D17467), PRla (Cutt et al. 1988) (X12485), hsr203j (Pontier et al. 1998) (X77136), and $E A H$ (Ralston et al. 2001) (AF368376).

\section{RT-PCR.}

Total RNAs were isolated from $N$. benthamiana leaves using TRIzol Reagent (Invitrogen, Carlsbad, CA, U.S.A.) according to the manufacturer's recommendations. cDNA synthesis was conducted using a commercial kit (ReverTra Ace- $\alpha-$; Toyobo, Osaka, Japan) and PCR was performed with GoTaq Master Mix (Promega Corp., Madison, WI, U.S.A.). The thermocycle conditions used were one cycle at $94^{\circ} \mathrm{C}$ for $2 \mathrm{~min}$; and $x$ cycles of $94^{\circ} \mathrm{C}$ for $30 \mathrm{~s}, 55^{\circ} \mathrm{C}$ for $30 \mathrm{~s}\left(50^{\circ} \mathrm{C}\right.$ for $\left.N b E I N 2\right), 72^{\circ} \mathrm{C}$ for 1 min (per kilobase), and $72^{\circ} \mathrm{C}$ for $5 \mathrm{~min}$. Gene-specific primer (Supplementary Table 1) combinations used and the number of PCR cycles for expression analysis were as follows: ICS1-F-H and GE-ICS1-R (NbICS1), 25 cycles; GE-EIN2-F and GEEIN2-R (NbEIN2), 32 cycles; NPR1-F-H and GE-NPR1-R (NbNPR1), 25 cycles; COI1-F-C and GE-COI1-R (NbCOI1), 25 cycles; GE-VPE-F and VPE-R-B (NbVPE), 25 cycles; GEPR-1a-F and PR-1a-R (NbPR-1a), 25 cycles; GE-HSR203J-F and GE-HSR203J-R (Nbhsr203j), 25 cycles; EAS-F-H and GE-EAS-R (NbEAS), 18 cycles; EAH-F and GE-EAH-R $(N b E A H), 20$ cycles; PAL-F and GE-PAL-R (NbPAL), 25 cycles; and EF1 $\alpha-\mathrm{F}$ and EF1 $\alpha-\mathrm{R}(N b E F-1 \alpha), 23$ cycles. The PCR products were separated on a $1.8 \%$ agarose gel and visualized under UV illumination after ethidium bromide staining.

\section{Preparation of silencing constructs.}

Partial cDNA of $N b P A L, N b V P E, N b P R-1 a, N b E A S$, and $N b E A H$ was amplified from $N$. benthamiana cDNA using gene-specific primers with restriction sites at the $5^{\prime}$ ends. The gene-specific primer combinations used to construct the silencing vectors were as follows: VPE-F-C and VPE-R-B (NbVPE), PAL-F and PAL-R (NbPAL), PR-1a-F and PR-1a-R (NbPR$1 a)$, EAS-F-H and EAS-R-B (NbEAS), and EAH-F and EAH$\mathrm{R}(N b E A H)$. Amplified fragments were digested with restriction enzymes and ligated into the pTV00 vector (Ratcliff et al. 2001) digested with compatible restriction enzymes to generate pTV00:PAL, pTV00:VPE, pTV00:PR-1a, pTV00:EAS, and pTV00:EAH. For all constructs, the inserts were amplified and sequenced to confirm cloning of the correct gene fragment. Construction of silencing vectors for NbICS1, NbNPR1, $N b C O I 1$, and NbEIN2 has been reported previously (Uruma et al. 2009). The pTV00 vectors were transformed into Agrobacterium tumefaciens (strain GV3101, with helper plasmid pSoup) by electroporation with a MicroPulser electroporator (Bio-Rad, Hercules, CA, U.S.A.) and transformants were selected on LB media with rifampicin at $50 \mu \mathrm{g} / \mathrm{ml}$, kanamycin at $50 \mu \mathrm{g} / \mathrm{ml}$, and tetracycline at $2.5 \mu \mathrm{g} / \mathrm{ml}$.

\section{VIGS.}

Induction of VIGS was performed as previously reported (Ratcliff et al. 2001). A. tumefaciens GV3101, carrying the binary TRV RNA 1 construct pBINTRA6 and the TRV RNA2 vector pTV00 or pTV00 derivatives, was cultured to saturation in LB medium. Bacterial suspensions were then collected by centrifugation at $16,000 \times g$ for $1 \mathrm{~min}$. The bacterial cells were then resuspended in $10 \mathrm{mM}$ morpholineethane sulfonic acid (MES)-NaOH (pH 5.6), $10 \mathrm{mM} \mathrm{MgCl}_{2}$, and $150 \mu \mathrm{M}$ acetosyringone (final $\mathrm{OD}_{600}=0.5$ ) and incubated at room temperature for $2 \mathrm{~h}$. The cultures were mixed in a 1:1 ratio (RNA1/RNA2) to infiltrate leaves of $N$. benthamiana using a syringe without a needle. Three to four weeks after infiltration, the upper leaves of the inoculated plants were used for experiments.

\section{Construction of vectors for agroinfiltration.}

Genes for mature $P$. infestans INF1 or NPP1.1 (without the $\mathrm{N}$-terminal signal peptide) were amplified from genomic DNA of $P$. infestans PI0-1 with primers INF1-F-B and INF1-R-Sp or NPP1-F-B and NPP1-R-Sp, respectively. The signal peptides 
for tobacco PR1a, XbaI-SpPR1-BamHI, from pCBJ-sp-capsicine (Takemoto et al. 2005), BamHI-INF1-SphI (or BamHINPP1.1-SphI), and SphI-HA/Str2-EcoRI (hemagglutinin tag YPYDVPDYA [Kolodziej and Young 1991] followed by a Strep tag II WSHPQFEK, [Schmidt and Skerra 1993]) were subsequently cloned into the $X b a \mathrm{I}-E c o$ RI site of $\mathrm{pEl} 2 \Omega$ vector

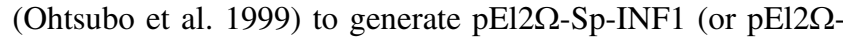
Sp-NPP1.1). The $\mathrm{pEl} 2 \Omega$ vectors were transformed into A. tumefaciens (rifampicin-resistant strain $\mathrm{C} 58 \mathrm{C} 1$ ) by electroporation with a MicroPulser electroporator (Bio-Rad). A. tumefaciens transformants were selected on LB media with rifampicin at $50 \mu \mathrm{g} / \mathrm{ml}$, kanamycin at $50 \mu \mathrm{g} / \mathrm{ml}$, and ampicillin at $50 \mu \mathrm{g} / \mathrm{ml}$.

\section{Transient gene expression by agroinfiltration.}

A. tumefaciens carrying the $\mathrm{pEl} 2 \Omega$ construct was cultured to saturation in LB medium and bacterial cells were collected by centrifugation at $16,000 \times g$ for $1 \mathrm{~min}$. The bacterial cells were then resuspended in MMA infiltration medium (MS salts at 5 $\mathrm{mg} / \mathrm{ml}, \mathrm{MES}$ at $1.95 \mathrm{mg} / \mathrm{ml}$, sucrose at $20 \mathrm{mg} / \mathrm{ml}$, and $200 \mu \mathrm{M}$ acetosyringone, $\mathrm{pH}=5.6$ ) to a final $\mathrm{OD}_{600}$ of 0.5 and incubated at room temperature for $2 \mathrm{~h}$. The cultures were allowed to infiltrate the intercellular space of $N$. benthamiana leaves using a syringe without a needle.

\section{Protein extraction and immunoblotting.}

$N$. benthamiana leaf tissue was harvested at $48 \mathrm{~h}$ after inoculation with $A$. tumefaciens and stored at $-80^{\circ} \mathrm{C}$ after fixing in liquid nitrogen. Protein extracts from $N$. benthamiana leaves were prepared by grinding them in a buffer consisting of: 50 mM MOPS, 0.5 M sorbitol, 5 mM EDTA, 5 mM EGTA, 100 $\mathrm{mM} \mathrm{NaF}$, and $100 \mu \mathrm{M} \mathrm{Na}_{3} \mathrm{VO}_{4}, \mathrm{pH} 7.6$, and containing a protease inhibitor cocktail (Sigma-Aldrich, St. Louis,). Supernatants were cleared by centrifugation at $16,000 \times g$ for $10 \mathrm{~min}$ at $4^{\circ} \mathrm{C}$ and stored in $\mathrm{a}-80^{\circ} \mathrm{C}$ freezer. Protein concentration was determined using the Protein Assay (Bio-Rad) with bovine serum albumin as a standard. HA-tagged INF1 and NPP1.1 expressed in $N$. benthamiana leaves were detected by immunoblotting performed as described by Kato and associates (2008) using monoclonal HA antibodies (Roche) and anti-mouse immunoglobulin G antibody (GE Healthcare).

\section{ROS measurement.}

The relative intensity of ROS generation was determined by counting photons from L-012-mediated chemiluminescence. L012 (Wako, Osaka, Japan) is a luminol derivative that is highly sensitive to superoxide anion $\left(\mathrm{O}_{2}^{-}\right)$(Asai et al. 2008; Nishinaka et al. 1993). To detect the ROS production in $N$. benthamiana leaves, $0.5 \mathrm{mM} \mathrm{L-012}$ in $10 \mathrm{mM}$ MOPS-KOH (pH 7.4) was allowed to infiltrate to the intercellular space of leaves via a syringe without needle. Chemiluminescence was monitored continuously using a photon image processor equipped with a sensitive CCD camera in a dark chamber at $20^{\circ} \mathrm{C}$ (Aquacosmos 2.5; Hamamatsu Photonics, Shizuoka, Japan), and quantified using the U7501 program (Hamamatsu Photonics).

\section{Microscopy.}

To visualize plant cell death and colonization of $P$. infestans, leaves of $N$. benthamiana were stained with lactophenol trypan blue as described by Takemoto and associates (2003) with a minor modification. Briefly, infected leaves were cleared in methanol overnight, and then the cleared tissue was boiled for $2 \mathrm{~min}$ in lactophenol trypan blue stain $\left(10 \mathrm{ml}\right.$ of $\mathrm{H}_{2} \mathrm{O}, 10 \mathrm{ml}$ of lactic acid, $10 \mathrm{ml}$ of glycerol, $10 \mathrm{~g}$ of phenol, and $10 \mathrm{mg}$ of trypan blue). After the leaves had been allowed to cool at room temperature for $1 \mathrm{~h}$, the stain was replaced with chloral hydrate at $1 \mathrm{~g} / \mathrm{ml}$. Stained leaves were monitored using an Olympus microscope BX51 (Olympus, Tokyo).

\section{ACKNOWLEDGMENTS}

We thank D. C. Baulcombe (University of Cambridge, Cambridge, MA, U.S.A.) for providing pTV00 and pBINTRA6 vectors, S. Kamoun (The Sainsbury Laboratory, Norwich, U.K.) for pFB53 vector, I. Mitsuhara for pE12 $\Omega$ vector, D. A. Jones (The Australian National University, Canberra, Australia) and the Leaf Tobacco Research Center (Japan Tobacco Inc., Tokyo) for N. benthamiana seed, S. Akino (Hokkaido University, Sapporo, Japan) and K. Shirai (Hokkaido Central Agricultural Experiment Station, Naganuma, Japan) for providing $P$. infestans isolates, M. Mori and S. Tsuda (National Agricultural Research Center for Hokkaido Region, Memuro, Japan) and Y. Tahara (Nagoya University, Nagoya, Japan) for providing potato tubers, H. Mori (Nagoya University) for technical advice, and M. Lane (Massey University, Palmerston North, New Zealand) for English editing of the manuscript. This work was supported by a Grantin-Aid for Young Scientists (B) (20780032) and Grant-in Aid for Scientific Research (B) (18380032) from the Japan Society for the Promotion of Science.

\section{LITERATURE CITED}

Alonso, J. M., Hirayama, T., Roman, G., Nourizadeh, S., and Ecker, J. R. 1999. EIN2, a bifunctional transducer of ethylene and stress responses in Arabidopsis. Science 284:2148-2152.

Asai, S., Ohta, K., and Yoshioka, H. 2008. MAPK signaling regulates nitric oxide and NADPH oxidase-dependent oxidative bursts in Nicotiana benthamiana. Plant Cell 20:1390-1406.

Bailey, J. A., Burden, R. S., and Vincent, G. G. 1975. Capsidiol: Antifungal compound produced in Nicotiana tabacum and Nicotiana clevelandii following infection with tobacco necrosis virus. Phytochemistry 14:597-597.

Ballvora, A., Ercolano, M. R., Weiß, J., Meksem, K., Bormann, C. A., Oberhagemann, P., Salamini, F., and Gebhardt, C. 2002. The $R 1$ gene for potato resistance to late blight (Phytophthora infestans) belongs to the leucine zipper/NBS/LRR class of plant resistance genes. Plant J. 30:361-371.

Bate, N. J., Orr, J., Ni, W., Meromi, A., Nadler-Hassar, T., Doerner, P. W., Dixon, R. A., Lamb, C. J., and Elkind, Y. 1994. Quantitative relationship between phenylalanine ammonia-lyase levels and phenylpropanoid accumulation in transgenic tobacco identifies a rate-determining step in natural product synthesis. Proc. Natl. Acad. Sci. U.S.A. 91:7608-7612.

Becktell, M. C., Smart, C. D., Haney, C. H., and Fry, W. E. 2006. Hostpathogen interactions between Phytophthora infestans and the Solanaceous hosts Calibrachoa $\times$ hybridus, Petunia $\times$ hybrida, and Nicotiana benthamiana. Plant Dis. 90:24-32.

Blein, J.-P., Coutos-Thévenot, P., Marion, D., and Ponchet, M. 2002. From elicitins to lipid-transfer proteins: A new insight in cell signalling involved in plant defence mechanisms. Trends Plant Sci. 7:293-296.

Cao, H., Glazebrook, J., Clarke, J. D., Volko, S., and Dong, X. 1997. The Arabidopsis NPR1 gene that controls systemic acquired resistance encodes a novel protein containing ankyrin repeats. Cell 88:57-63.

Catinot, J., Buchala, A., Abou-Mansour, E., and Métraux, J.-P. 2008. Salicylic acid production in response to biotic and abiotic stress depends on isochorismate in Nicotiana benthamiana. FEBS (Fed. Eur. Biochem. Soc.) Lett. 582:473-478.

Century, K. S., Lagman, R. A., Adkisson, M., Morlan, J., Tobias, R., Schwartz, K., Smith, A., Love, J., Ronald, P. C., and Whalen, M. C. 1999. Developmental control of Xa21-mediated disease resistance in rice. Plant J. 20:231-236.

CIP. 1996. The International Potato Center Annual Report. Lima, Peru.

Cornelissen, B. J. C., Horowitz, J., Vankan, J. A. L., Goldberg, R. B., and Bol, J. F. 1987. Structure of tobacco genes encoding pathogenesisrelated proteins from the PR-1 group. Nucleic Acids Res. 15:67996811.

Cutt, J. R., Dixon, D. C., Carr, J. P., and Klessig, D. F. 1988. Isolation and nucleotide sequence of cDNA clones for the pathogenesis-related proteins PR1a, PR1b and PR1c of Nicotiana tabacum cv. Xanthi nc induced by TMV infection. Nucleic Acids Res. 16:9861.

Develey-Rivière, M., and Galiana, E. 2007. Resistance to pathogens and host developmental stage: A multifaceted relationship within the plant kingdom. New Phytol. 175:405-416.

Doke, N. 1975. Prevention of the hypersensitive reaction of potato cells to infection with an incompatible race of Phytophthora infestans by constituents of the zoospores. Physiol. Plant Pathol. 7:1-7.

Doke, N. 1983. Involvement of superoxide anion generation in the hypersensitive response of potato tuber tissues to infection with an incompatible race of Phytophthora infestans and to the hyphal wall components. Physiol. Plant Pathol. 23:345-357.

Doke, N., Miura, Y., Sanchez, L. M., Park, H.-J., Noritake, T., Yoshioka, 
H., and Kawakita, K. 1996. The oxidative burst protects plants against pathogen attack: Mechanism and role as an emergency signal for plant bio-defence-a review. Gene 179:45-51.

Facchini, P. J., and Chappell, J. 1992. Gene family for an elicitor-induced sesquiterpene cyclase in tobacco. Proc. Natl. Acad. Sci. U.S.A. 89:11088-11092.

Fellbrich, G., Romanski, A., Varet, A., Blume, B., Brunner, F., Engelhardt, S., Felix, G., Kemmerling, B., Krzymowska, M., and Nürnberger, T. 2002. NPP1, a Phytophthora-associated trigger of plant defense in parsley and Arabidopsis. Plant J. 32:375-390.

Ferrari, S., Plotnikova, J. M., De Lorenzo, G., and Ausubel, F. M. 2003. Arabidopsis local resistance to Botrytis cinerea involves salicylic acid and camalexin and requires EDS4 and PAD2, but not SID2, EDS5 or PAD4. Plant J. 35:193-205.

Glazebrook, J. 2005. Contrasting mechanisms of defense against biotrophic and necrotrophic pathogens. Annu. Rev. Phytopathol. 43:205-227.

Glazebrook, J., Zook, M., Mert, F., Kagan, I., Rogers, E. E., Crute, I. R., Holub, E. B., Hammerschmidt, R., and Ausubel, F. M. 1997. Phytoalexin-deficient mutants of Arabidopsis reveal that PAD4 encodes a regulatory factor and that four $P A D$ genes contribute to downy mildew resistance. Genetics 146:381-392.

Gross, J., Cho, W. K., Lezhneva, L., Falk, J., Krupinska, K., Shinozaki, K., Seki, M., Herrmann, R. G., and Meurer, J. 2006. A plant locus essential for phylloquinone (vitamin $\mathrm{K}_{1}$ ) biosynthesis originated from a fusion of four eubacterial genes. J. Biol. Chem. 281:17189-17196.

Hahlbrock, K., Bednarek, P., Ciolkowski, I., Hamberger, B., Heise, A., Liedgens, H., Logemann, E., Nürnberger, T., Schmelzer, E., Somssich, I. E., and Tan, J. 2003. Non-self recognition, transcriptional reprogramming, and secondary metabolite accumulation during plant/pathogen interactions. Proc. Natl. Acad. Sci. U.S.A. 100 (Suppl. 2):14569-14576.

Hammerschmidt, R. 1999. Phytoalexins: What have we learned after 60 years? Annu. Rev. Phytopathol. 37:285-306.

Hara-Nishimura, I., Inoue, K., and Nishimura, M. 1991. A unique vacuolar processing enzyme responsible for conversion of several proprotein precursors into the mature forms. FEBS (Fed. Eur. Biochem. Soc.) Lett. 294:89-93.

Hatsugai, N., Kuroyanagi, M., Yamada, K., Meshi, T., Tsuda, S., Kondo, M., Nishimura, M., and Hara-Nishimura, I. 2004. A plant vacuolar protease, VPE, mediates virus-induced hypersensitive cell death. Science 305:855-858.

Hugot, K., Aimé, S., Conrod, S., Poupet, A., and Galiana, E. 1999. Developmental regulated mechanisms affect the ability of a fungal pathogen to infect and colonize tobacco leaves. Plant J. 20:163-170.

Jones, D. A., and Takemoto, D. 2004. Plant innate immunity-direct and indirect recognition of general and specific pathogen-associated molecules. Curr. Opin. Immunol. 16:48-62.

Kamoun, S., Klucher, K. M., Coffey, M. D., and Tyler, B. M. 1993. A gene encoding a host-specific elicitor protein of Phytophthora parasitica. Mol. Plant-Microbe Interact. 6:573-581.

Kamoun, S., van West, P., de Jong, A. J., de Groot, K. E., Vleeshouwers, V. G. A. A., and Govers, F. 1997. A gene encoding a protein elicitor of Phytophthora infestans is down-regulated during infection of potato. Mol. Plant-Microbe Interact. 10:13-20.

Kamoun, S., van West, P., Vleeshouwers, V. G. A. A., de Groot, K. E., and Govers, F. 1998. Resistance of Nicotiana benthamiana to Phytophthora infestans is mediated by the recognition of the elicitor protein INF1. Plant Cell 10:1413-1425.

Kanneganti, T.-D., Huitema, E., Cakir, C., and Kamoun, S. 2006. Synergistic interactions of the plant cell death pathways induced by Phytophthora infestans Nep1-like protein PiNPP1.1 and INF1 elicitin. Mol. Plant-Microbe Interact. 19:854-863.

Kato, H., Asai, S., Yamamoto-Katou, A., Yoshioka, H., Doke, N., and Kawakita, K. 2008. Involvement of NbNOA1 in NO production and defense responses in INF1-treated Nicotiana benthamiana. J. Gen. Plant Pathol. 74:15-23.

Kitazawa, K., and Tomiyama, K. 1969. Microscopic observations of infection of potato cells by compatible and incompatible races of Phytophthora infestans. J. Phytopathol. 66:317-324.

Kobae, Y., Sekino, T., Yoshioka, H., Nakagawa, T., Martinoia, E., and Maeshima, M. 2006. Loss of AtPDR8, a plasma membrane ABC transporter of Arabidopsis thaliana, causes hypersensitive cell death upon pathogen infection. Plant Cell Physiol. 47:309-318.

Kolodziej, P. A., and Young, R. A. 1991. Epitope tagging and protein surveillance. Methods Enzymol. 194:508-519.

Kuhl, J. C., Hanneman, R. E. Jr., Havey, M. J. 2001. Characterization and mapping of Rpi1, a late-blight resistance locus from diploid (1EBN) Mexican Solanum pinnatisectum. Mol. Genet. Genomics 265:977-985.

León, J., Yalpani, N., Raskin, I., and Lawton, M. A. 1993. Induction of benzoic acid 2-hydroxylase in virus-inoculated tobacco. Plant Physiol. 103:323-328
Lherminier, J., Elmayan, T., Fromentin, J., Elaraqui, K. T., Vesa, S., Morel, J., Verrier, J.-L., Cailleteau, B., Blein, J.-P., and Simon-Plas, F. 2009. NADPH oxidase-mediated reactive oxygen species production: Subcellular localization and reassessment of its role in plant defense. Mol. Plant-Microbe Interact. 22:868-881.

Lipka, V., Dittgen, J., Bednarek, P., Bhat, R., Wiermer, M., Stein, M., Landtag, J., Brandt, W., Rosahl, S., Scheel, D., Llorente, F., Molina, A. Parker, J., Somerville, S., and Schulze-Lefert, P. 2005. Pre- and postinvasion defenses both contribute to nonhost resistance in Arabidopsis. Science 310:1180-1183.

Liu, Y. L., Schiff, M., Marathe, R., and Dinesh-Kumar, S. P. 2002. Tobacco Rar1, EDS1 and NPR1/NIM1 like genes are required for $N$-mediated resistance to Tobacco mosaic virus. Plant J. 30:415-429.

Liu, Y., Schiff, M., and Dinesh-Kumar, S. P. 2004. Involvement of MEK1 MAPKK, NTF6 MAPK, WRKY/MYB transcription factors, COI1 and CTR1 in $\mathrm{N}$-mediated resistance to Tobacco mosaic virus. Plant $\mathrm{J}$. 38:800-809.

Maldonado-Bonilla, L. D., Betancourt-Jiménez, M., and Lozoya-Gloria E. 2008. Local and systemic gene expression of sesquiterpene phytoalexin biosynthetic enzymes in plant leaves. Eur. J. Plant Pathol. 121:439-449.

Mauch-Mani, B., and Slusarenko, A. J. 1996. Production of salicylic acid precursors is a major function of phenylalanine ammonia-lyase in the resistance of Arabidopsis to Peronospora parasitica. Plant Cell 8:203212.

McDowell, J. M., and Dangl, J. L. 2000. Signal transduction in the plant immune response. Trends Biochem. Sci. 25:79-82.

McDowell, J. M., Williams, S. G., Funderburg, N. T., Eulgem, T., and Dangl, J. L. 2005. Genetic analysis of developmentally regulated resistance to downy mildew (Hyaloperonospora parasitica) in Arabidopsis thaliana. Mol. Plant-Microbe Interact. 18:1226-1234.

Milat, M.-L., Ricci, P., Bonnet, P., and Blein, J.-P. 1991. Capsidiol and ethylene production by tobacco cells in response to cryptogein, an elicitor from Phytophthora cryptogea. Phytochemistry 30:2171-2173.

Nagai, N., Kitauchi, F., Okamoto, K., Kanda, T., Shimosaka, M., and Okazaki, M. 1994. A transient increase of phenylalanine ammonia-lyase transcript in kinetin-treated tobacco callus. Biosci. Biotechnol. Biochem. 58:558-559.

Nawrath, C., and Métraux, J.-P. 1999. Salicylic acid induction-deficient mutants of Arabidopsis express $P R-2$ and $P R-5$ and accumulate high levels of camalexin after pathogen inoculation. Plant Cell 11:1393-1404.

Nishinaka, Y., Aramaki, Y., Yoshida, H., Masuya, H., Sugawara, T., and Ichimori, Y. 1993. A new sensitive chemiluminescence probe, L-012, for measuring the production of superoxide anion by cells. Biochem. Biophys. Res. Commun. 193:554-559.

Ogawa, D., Nakajima, N., Sano, T., Tamaoki, M., Aono, M., Kubo, A. Kanna, M., Ioki, M., Kamada, H., and Saji, H. 2005. Salicylic acid accumulation under $\mathrm{O}_{3}$ exposure is regulated by ethylene in tobacco plants. Plant Cell Physiol. 46:1062-1072.

Oh, S.-K., Young, C., Lee, M., Oliva, R., Bozkurt, T. O., Cano, L. M., Win, J., Bos, J. I. B., Liu, H.-Y., van Damme, M., Morgan, W., Choi, D., Van der Vossen, E. A. G., Vleeshouwers, V. G. A. A., and Kamoun, S. 2009. In planta expression screens of Phytophthora infestans RXLR effectors reveal diverse phenotypes, including activation of the Solanum bulbocastanum disease resistance protein Rpi-blb2. Plant Cell 21:2928-2947.

Ohtsubo, N., Mitsuhara, I., Koga, M., Seo, S., and Ohashi, Y. 1999. Ethylene promotes the necrotic lesion formation and basic PR gene expression in TMV-infected tobacco. Plant Cell Physiol. 40:808-817.

Overmyer, K., Brosché, M., and Kangasjärvi, J. 2003. Reactive oxygen species and hormonal control of cell death. Trends Plant Sci. 8:335-342.

Pallas, J. A., Paiva, N. L., Lamb, C., and Dixon, R. A. 1996. Tobacco plants epigenetically suppressed in phenylalanine ammonia-lyase expression do not develop systemic acquired resistance in response to infection by tobacco mosaic virus. Plant J. 10:281-293.

Panter, S. N., and Jones, D. A. 2002. Age-related resistance to plant pathogens. Adv. Bot. Res. 38:251-280.

Panter, S. N., Hammond-Kosack, K. E., Harrison, K., Jones, J. D. G., and Jones, D. A. 2002. Developmental control of promoter activity is not responsible for mature onset of $C f-9 B$-mediated resistance to leaf mold in tomato. Mol. Plant-Microbe Interact. 15:1099-1107.

Pieterse, C. M. J., and Van Loon, L. C. 2004. NPR1: The spider in the web of induced resistance signaling pathways. Curr. Opin. Plant Biol. 7:456464.

Pogány, M., von Rad, U., Grün, S., Dongó, A., Pintye, A., Simoneau, P., Bahnweg, G., Kiss, L., Barna, B., and Durner, J. 2009. Dual roles of reactive oxygen species and NADPH oxidase RBOHD in an Arabidopsis-Alternaria pathosystem. Plant Physiol. 151:1459-1475.

Pontier, D., Tronchet, M., Rogowsky, P., Lam, E., and Roby, D. 1998. Activation of $h s r 203$, a plant gene expressed during incompatible plantpathogen interactions, is correlated with programmed cell death. Mol Plant-Microbe Interact. 11:544-554. 
Ralston, L., Kwon, S. T., Schoenbeck, M., Ralston, J., Schenk, D. J., Coates, R. M., and Chappell, J. 2001. Cloning, heterologous expression, and functional characterization of 5-epi-aristolochene-1,3-dihydroxylase from tobacco (Nicotiana tabacum). Arch. Biochem. Biophys. 393:222-235.

Ratcliff, F., Martin-Hernandez, A. M., and Baulcombe, D. C. 2001. Tobacco rattle virus as a vector for analysis of gene function by silencing. Plant J. 25:237-245.

Reuber, T. L., Plotnikova, J. M., Dewdney, J., Rogers, E. E., Wood, W. and Ausubel, F. M. 1998. Correlation of defense gene induction defects with powdery mildew susceptibility in Arabidopsis enhanced disease susceptibility mutants. Plant J. 16:473-485.

Ribnicky, D. M., Shulaev, V., and Raskin, I. 1998. Intermediates of salicylic acid biosynthesis in tobacco. Plant Physiol. 118:565-572.

Rivière, M.-P., Marais, A., Ponchet, M., Willats, W., and Galiana E. 2008. Silencing of acidic pathogenesis-related $P R-1$ genes increases extracellular $\beta$-(1-3)-glucanase activity at the onset of tobacco defence reactions. J. Exp. Bot. 59:1225-1239.

Rusterucci, C., Zhao, Z., Haines, K., Mellersh, D., Neumann, M., and Cameron, R. K. 2005. Age-related resistance to Pseudomonas syringae pv. tomato is associated with the transition to flowering in Arabidopsis and is effective against Peronospora parasitica. Physiol. Mol. Plant Pathol. 66:222-231.

Schmidt, T. G. M., and Skerra, A. 1993. The random peptide libraryassisted engineering of a C-terminal affinity peptide, useful for the detection and purification of a functional Ig Fv fragment. Protein Eng. 6:109-122.

Serino, L., Reimmann, C., Baur, H., Beyeler, M., Visca, P., and Haas, D. 1995. Structural genes for salicylate biosynthesis from chorismate in Pseudomonas aeruginosa. Mol. Gen. Genet. 249:217-228.

Shah, J. 2003. The salicylic acid loop in plant defense. Curr. Opin. Plant Biol. 6:365-371.

Simon-Plas, F., Elmayan, T., and Blein, J.-P. 2002. The plasma membrane oxidase NtrbohD is responsible for AOS production in elicited tobacco cells. Plant J. 31:137-147.

Song, J., Bradeen, J. M., Naess, S. K., Raasch, J. A., Wielgus, S. M., Haberlach, G. T., Liu, J., Kuang, H., Austin-Phillips, S., Buell, C. R., Helgeson, J. P., and Jiang, J. 2003. Gene RB cloned from Solanum bulbocastanum confers broad spectrum resistance to potato late blight. Proc. Natl. Acad. Sci. U.S.A. 100:9128-9133.

Steffens, B., and Sauter, M. 2009. Epidermal cell death in rice is confined to cells with a distinct molecular identity and is mediated by ethylene and $\mathrm{H}_{2} \mathrm{O}_{2}$ through an autoamplified signal pathway. Plant Cell 21:184196

Stein, M., Dittgen, J., Sánchez-Rodríguez, C., Hou, B.-H., Molina, A., Schulze-Lefert, P., Lipka, V., and Somerville, S. 2006. Arabidopsis PEN3/PDR8, an ATP binding cassette transporter, contributes to nonhost resistance to inappropriate pathogens that enter by direct penetration. Plant Cell 18:731-746.

Takemoto, D., Jones, D. A., and Hardham, A. R. 2003. GFP-tagging of cell components reveals the dynamics of subcellular re-organization in response to infection of Arabidopsis by oomycete pathogens. Plant J. 33:775-792.

Takemoto, D., Hardham, A. R., and Jones, D. A. 2005. Differences in cell death induction by Phytophthora elicitins are determined by signal components downstream of MAP kinase kinase in different species of Nicotiana and cultivars of Brassica rapa and Raphanus sativus. Plant Physiol. 138:1491-1504.

Thatcher, L. F., Anderson, J. P., and Singh, K. B. 2005. Plant defence responses: What have we learnt from Arabidopsis? Funct. Plant Biol. 32:1-19
Thomma, B. P. H. J., Nelissen, I., Eggermont, K., and Broekaert, W. F. 1999. Deficiency in phytoalexin production causes enhanced susceptibility of Arabidopsis thaliana to the fungus Alternaria brassicicola. Plant J. 19:163-171.

Torres, M. A., and Dangl, J. L. 2005. Functions of the respiratory burst oxidase in biotic interactions, abiotic stress and development. Curr. Opin. Plant Biol. 8:397-403.

Torres, M. A., Dangl, J. L., and Jones, J. D. G. 2002. Arabidopsis gp91 ${ }^{\text {phox }}$ homologues AtrbohD and AtrbohF are required for accumulation of reactive oxygen intermediates in the plant defense response. Proc. Natl. Acad. Sci. U.S.A. 99:517-522.

Umaerus, V., and Umaerus, M. 1994. Inheritance of resistance to late blight. Pages 365-401. in: Potato Genetics. J. E. Bradshaw and G. R. Mackay, eds. CAB International, Wallingford, U.K.

Uruma, S., Shibata, Y., Takemoto, D., and Kawakita, K. 2009. N,Ndimethylsphingosine, an inhibitor of sphingosine kinase, induces phytoalexin production and hypersensitive cell death of Solanaceae plants without generation of reactive oxygen species. J. Gen. Plant Pathol. 75:257-266.

Vallad, G. E., and Goodman, R. M. 2004. Systemic acquired resistance and induced systemic resistance in conventional agriculture. Crop Sci. 44:1920-1934.

van der Vossen, E. A. G., Gros, J., Sikkema, A., Muskens, M., Wouters, D. Wolters, P., Pereira, A., and Allefs, S. 2005. The Rpi-blb2 gene from Solanum bulbocastanum is an Mi-1 gene homolog conferring broadspectrum late blight resistance in potato. Plant J. 44:208-222.

van Wees, S. C. M., Chang, H.-S., Zhu, T., and Glazebrook, J. 2003. Characterization of the early response of Arabidopsis to Alternaria brassicicola infection using expression profiling. Plant Physiol. 132:606-617.

Vlot, A. C., Dempsey, D. A., and Klessig, D. F. 2009. Salicylic acid, a multifaceted hormone to combat disease. Annu. Rev. Phytopathol. 47:177-206.

Westphal, L., Scheel, D., and Rosahl, S. 2008. The coil-16 mutant harbors a second site mutation rendering PEN2 nonfunctional. Plant Cell 20:824-826.

Wildermuth, M., Dewdney, J., Wu, G., and Ausubel, F. M. 2001. Isochorismate synthase is required to synthesize salicylic acid for plant defence. Nature 414:562-565.

Wu, S., Schoenbeck, M. A., Greenhagen, B. T., Takahashi, S., Lee, S., Coates, R. M., and Chappell, J. 2005. Surrogate splicing for functional analysis of sesquiterpene synthase genes. Plant Physiol. 138:13221333.

Xie, D.-X., Feys, B. F., James, S., Nieto-Rostro, M., and Turner, J. G. 1998. COI1: An Arabidopsis gene required for jasmonate-regulated defense and fertility. Science 280:1091-1094

Yalpani, N., Silverman, P., Wilson, T. M. A., Kleier, D. A., and Raskin, I. 1991. Salicylic acid is a systemic signal and an inducer of pathogenesisrelated proteins in virus-infected tobacco. Plant Cell 3:809-818.

Yoshie, Y., Goto, K., Takai, R., Iwano, M., Takayama, S., Isogai. A., and Che, F.-S. 2005. Function of the rice gp91 homologs OsrbohA and OsrbohE genes in ROS-dependent plant immune responses. Plant Biotech. 22:127-135.

Yoshioka, H., Numata, N., Nakajima, K., Katou, S., Kawakita, K., Rowland, O., Jones, J. D. G., and Doke, N. 2003. Nicotiana benthamiana gp91 ${ }^{\text {phox }}$ homologs NbrbohA and NbrbohB participate in $\mathrm{H}_{2} \mathrm{O}_{2}$ accumulation and resistance to Phytophthora infestans. Plant Cell 15:706-718.

\section{AUTHOR-RECOMMENDED INTERNET RESOURCE}

Plant genome database (PlantGDB) website: plantgdb.org 